\title{
Mapping within-field leaf chlorophyll content in agricultural crops for nitrogen management using Landsat-8 imagery
}

\author{
Holly Croft ${ }^{1,2}$. Joyce Arabian ${ }^{1,3} \cdot$ Jing M. Chen ${ }^{1}$. Jiali Shang ${ }^{4}$ Jiangui Liu ${ }^{4}$ \\ Published online: 19 November 2019 \\ (c) The Author(s) 2019
}

\begin{abstract}
Spatial information on crop nutrient status is central for monitoring vegetation health, plant productivity and managing nutrient optimization programs in agricultural systems. This study maps the spatial variability of leaf chlorophyll content within fields with differing quantities of nitrogen fertilizer application, using multispectral Landsat-8 OLI data $(30 \mathrm{~m})$. Leaf chlorophyll content and leaf area index measurements were collected at 15 wheat (Triticum aestivum) sites and 13 corn (Zea mays) sites approximately every 10 days during the growing season between May and September 2013 near Stratford, Ontario. Of the 28 sites, 9 sites were within controlled areas of zero nitrogen fertilizer application. Hyperspectral leaf reflectance measurements were also sampled using an Analytical Spectral Devices FieldSpecPro spectroradiometer (400-2500 nm). A two-step inversion process was developed to estimate leaf chlorophyll content from Landsat-8 satellite data at the subfield scale, using linked canopy and leaf radiative transfer models. Firstly, at the leaf-level, leaf chlorophyll content was modelled using the PROSPECT model, using both hyperspectral and simulated mulitspectral Landsat- 8 bands from the same leaf sample. Hyperspectral and multispectral validation results were both strong $\left(\mathrm{R}^{2}=0.79, \mathrm{RMSE}=13.62 \mu \mathrm{g} / \mathrm{cm}^{2}\right.$ and $\mathrm{R}^{2}=0.81, \mathrm{RMSE}=9.45 \mu \mathrm{g} / \mathrm{cm}^{2}$, respectively). Secondly, leaf chlorophyll content was estimated from Landsat- 8 satellite imagery for 7 dates within the growing season, using PROSPECT linked to the 4-Scale canopy model. The Landsat-8 derived estimates of leaf chlorophyll content demonstrated a strong relationship with measured leaf chlorophyll values $\left(\mathrm{R}^{2}=0.64, \mathrm{RMSE}=16.18 \mu \mathrm{g} / \mathrm{cm}^{2}\right)$, and compared favourably to correlations between leaf chlorophyll and the best performing tested spectral vegetation index (Green Normalised Difference Vegetation Index, GNDVI; $\mathrm{R}^{2}=0.59$ ). This research provides an operational basis for modelling within-field variations in leaf chlorophyll content as an indicator of plant nitrogen stress, using a physically-based modelling approach, and opens up the possibility of exploiting a wealth of multispectral satellite data and UAV-mounted multispectral imaging systems.
\end{abstract}

Keywords Remote sensing · PROSPECT model · Multispectral · Reflectance · Hyperspectral $\cdot$ SAIL model

Holly Croft

h.croft@sheffield.ac.uk

Extended author information available on the last page of the article 


\section{Introduction}

In agricultural systems, the accurate spatial mapping of leaf chlorophyll content is important for monitoring vegetation health and plant stress, which can be used to guide fertiliser application in order to optimise crop yield and reduce excessive nutrient loss. Chlorophyll molecules facilitate the conversion of absorbed solar irradiance into stored chemical energy, through harvesting light energy and supply of electrons to the electron transport chain, which leads to the production of NADPH for the reactions of the Calvin-Benson Cycle (Croft and Chen 2018; Chen 2014). The amount of solar radiation absorbed by a leaf is largely a function of the foliar concentration of photosynthetic pigments, and low chlorophyll contents can limit the photosynthetic capacity and reduce primary productivity of the plant (Croft et al. 2017; Peng et al. 2011; Houborg et al. 2015b; Richardson et al. 2002). Chlorophyll content has also been demonstrated to have a strong relationship to leaf nitrogen content, due to the underlying investment of nitrogen in chlorophyll molecules (Sage et al. 1987). Nitrogen is an essential component of all proteins and nucleic acids and is essential to the development of new plant cells, crop growth and plant metabolic activity (Sinclair and Rufty 2012).

Leaf nitrogen is an important overlying regulator of vegetation productivity. In C3 plants over half of the leaf's total nitrogen content is usually invested in photosynthetic machinery (Niinemets and Sack 2006). In industrialized countries, the rapid rise in crop yields during the 1950s and 1960s was closely associated with increased nitrogen-based fertilizer application (Sinclair and Rufty 2012). However, excessive or ill-timed nitrogen application can cause contamination of rivers, lakes and unconfined aquifers through denitrification or leaching from the rhizosphere, leading to increased farming costs and reduced grain yield (Peng et al. 2010). Nitrogen must be supplied in appropriate quantities and accumulated by plants to prevent nitrogen deficiency, which can hinder crop growth due to lowered protein levels and decreased cell function (Sinclair and Rufty 2012). Maintaining plant nitrogen supply is affected not only by the availability of nitrogen in the soil, but also by the ability of plants to accumulate nitrogen, which is associated growth stage and rooting depth (Sinclair and Rufty 2012). Crops may not have the physiological ability to uptake and store all of the applied nitrogen, with only an estimated $30 \%-50 \%$ of nitrogen fertilizer taken up by crops (Tilman et al. 2002), necessitating an improved monitoring of crop nitrogen status for targeted fertiliser application. Nitrogen supply from the soil varies according to local soil properties and weather conditions, which vary annually and by field site (Rütting et al. 2018). As leaf nitrogen content is often well-correlated with leaf chlorophyll (Sage et al. 1987), a common approach is to estimate chlorophyll content, which is easier and more accurate to derive non-destructively, as an indicator of crop nitrogen status (Li et al. 2010; Haboudane et al. 2008). Thus, monitoring of chlorophyll content will be useful for optimising the timing, spatial location and the rate of fertilizer application in order to achieve high yields and minimizing nitrogen loss to the environment.

Remote sensing offers a resource-efficient means to model leaf nutrient content in a spatially-continuous manner, and at regular time-steps. Perhaps the most widely used approach for deriving chlorophyll content from remote sensing data is through spectral vegetation indices (Haboudane et al. 2002; Wu et al. 2008; Gitelson et al. 2005). Statistical models are created between measured chlorophyll content and spectral indices, which are formulated using reflectance at chlorophyll-sensitive wavelengths, and are usually normalized by reflectance in wavelengths that are sensitive to leaf or canopy structure (Blackburn and Ferwerda 2008). However, literature shows a lack of generality and applicability of vegetation 
indices, across species, plant functional types and different physiological conditions (Croft et al. 2014). Alternatively, physically-based methods have been employed to model the radiative transfer processes that underpin the structural and biochemical controls on canopy reflectance in order to estimate crop chlorophyll (Jacquemoud et al. 2009). Most agricultural studies have used a version of the original Scattering by Arbitrary Inclined Leaves (SAIL) model (Verhoef 1984) in conjunction with the Model of Leaf Optical Spectra Properties (PROSPECT) leaf model (Jacquemoud and Baret 1990). However, the 'ill-posed' inversion problem (Combal et al. 2003) denotes that the same canopy reflectance can be due to different combinations of leaf and canopy parameters and sun-viewing geometry, indicating the importance of a priori information to constrain the inversion (Kimes et al. 2000).

This research will assess the potential of using physically-based radiative transfer models for modelling leaf chlorophyll content at the sub-field scale, using multispectral Landsat-8 $(30 \mathrm{~m})$ satellite data. The fine spatial resolution, freely available access and the long term archive of the data from the Landsat series means that it is a remote sensing resource of unparalleled importance. However, both physically-based and empirical methods for modelling leaf chlorophyll content are usually focused on hyperspectral or narrowband reflectance, restricting the use of a wide range of sensors, including satellite and UAVmounted sensors alike, which typically sample the spectrum at fewer and wider spectral bands. Further, the lack of a chlorophyll-sensitive red-edge band $(\sim 720 \mathrm{~nm})$ in Landsat data makes its potential for modelling chlorophyll content uncertain. Whilst, a limited number of studies have demonstrated the potential of using Landsat data to model chlorophyll content using physically-based methods (Houborg et al. 2015a; Croft et al. 2015; $\mathrm{Wu}$ et al. 2010) it remains under-utilised for retrieving leaf biochemical information. Jacquemoud et al. (1995) also inverted the PROSAIL model (a combination of the SAIL and PROSPECT models; Jacquemoud et al. 2009) on simulated Landsat TM data using reflectance data from sugar beet crops. This study will test the use of multispectral Landsat satellite data for modelling chlorophyll content in two crops: winter wheat (Triticum aestivum) and corn (Zea mays), two of the major crops grown in Southern Ontario, Canada (Dong et al. 2017). The specific objectives of this research are to: (1) Develop a remote-sensing based method to assess sub-field scale nitrogen deficiency using multispectral satellite data; and (2) Improve the transferability of leaf chlorophyll retrieval methods to increase the accuracy of chlorophyll estimates across different crop types. This paper therefore seeks to demonstrate the potential of using multispectral satellite for informing nitrogen management over different crop types. It is hypothesised that: (i) multispectral reflectance data can be used to accurately model leaf chlorophyll content, (ii) physically-based modelling approaches will outperform empirical methods, and (iii) multispectral chlorophyll inversion methods can be operationally used to inform nitrogen management.

\section{Methods}

\section{Field sampling sites}

The field sites were located in two corn fields and two wheat fields, in Easthope Township, Ontario. This region is a highly productive agricultural area with $90 \%$ of the land being used for agricultural production (Reid et al. 2007). The soils in the area are mostly clay and silty loams and have good natural fertility (Schwan and Elliott 2010). The climate is 
humid continental with warm to hot summers (July mean air temperature $\sim 20.2{ }^{\circ} \mathrm{C}$ ). Winter wheat (Triticum aestivum), soybean (Glycine max), and corn (Zea mays) are the three major annual crops in the study area (Dong et al. 2017). Corn is usually sown in May and harvested between late September and early November. Winter wheat is usually seeded in late September to early October the previous year, germinating and growing to about $10 \mathrm{~cm}$ before snow fall in November. It goes dormant during winter months (November to following March), and grows again from late March to early April until harvest in late July-early August (Dong et al. 2017). A total of 13 sites were sampled in two corn fields (CE1 and CE2) and 15 sites in two winter wheat fields (WE1 and WE2). For the majority area of the fields, the recommended rate of fertiliser application by the Ontario Ministry of Agriculture, Food and Rural Affairs (OMAFRA) (www.omafra.gov.on.ca/english/crops/ soils/fertility.html) was applied ( $105 \mathrm{~kg} \mathrm{~N} \mathrm{ha}^{-1}$ in the form of $28 \%$ urea-ammonium nitrate for the winter wheat, and $134 \mathrm{~kg} \mathrm{~N} \mathrm{ha}^{-1}$ was applied for the corn), except for the control area in the CE1, WE1 and WE2 fields, where no nitrogen was applied (Table 1, Fig. 1).

Wheat and corn data were collected approximately every 10 days between May and August, and June and September, respectively, reflecting the growing seasons of the respective crops. Individual sampling sites and no-nitrogen plots are shown on Google Earth image (Fig. 1). Most study sites were at least $30 \mathrm{~m}$ apart and all sites were within a different Landsat satellite pixel.

\section{Field data collection}

Five representative leaves were sampled from the upper plant canopy at each sampling site for subsequent biochemical analysis and leaf reflectance measurements. Leaf samples were placed in plastic bags and kept at a temperature of $0{ }^{\circ} \mathrm{C}$ in dark conditions. The samples were then transported immediately back to the University of Toronto and processed within approximately 4 hours of sampling. Foliar chlorophyll was extracted using spectrophotometric grade $N, N$-dimethylformamide, and absorbance was measured at $663.8 \mathrm{~nm}, 646.8 \mathrm{~nm}$, and $480 \mathrm{~nm}$ using a Shimadzu UV-1700 spectrophotometer (Wellburn 1994; Croft et al. 2013; Croft et al. 2014). The measured chlorophyll content values for each sampling site were calculated as mean values from the five leaf samples per site collected on each sampling date. Leaf chlorophyll content was measured from

Table 1 Details of the field and sampling sites. Zero $\mathrm{N}$ sites refer to sites where no fertilizer was applied, $\mathrm{N}$ sites refer to sites that received recommended rate of fertilizer

\begin{tabular}{llllll}
\hline Field ID & Location & Crop type & Zero N sites & N sites \\
\hline WE1 & $\begin{array}{llll}43^{\circ} 29^{\prime} 33^{\prime \prime} \mathrm{N} \\
80^{\circ} 54^{\prime} 23^{\prime \prime} \mathrm{W}\end{array}$ & Wheat & WE1-01 & WE1-02 & WE1-26 \\
& & & WE1-36 & WE1-18 & WE1-50 \\
& & & WE1-38 & & WE2-52 \\
WE2 & $43^{\circ} 24^{\prime} 35^{\prime \prime} \mathrm{N}$ & Wheat & WE2-19 & WE2-01 & WE2-54 \\
& $80^{\circ} 48^{\prime} 43^{\prime \prime} \mathrm{W}$ & & WE2-50 & WE2-09 & WE2-20 \\
& & & WE2-55 & CE1-02 & CE1-06 \\
CE1 & $43^{\circ} 27^{\prime} 40^{\prime \prime} \mathrm{N}$ & Corn & CE1-01 & CE1-05 & CE1-07 \\
& $80^{\circ} 48^{\prime} 53^{\prime \prime} \mathrm{W}$ & & CE1-19 & CE2-01 & CE2-04 \\
& & & CE1-21 & CE2-02 & CE2-05 \\
CE2 & $43^{\circ} 27^{\prime} 40^{\prime \prime} \mathrm{N}$ & Corn & - & CE2-08 & CE2-11 \\
\hline
\end{tabular}



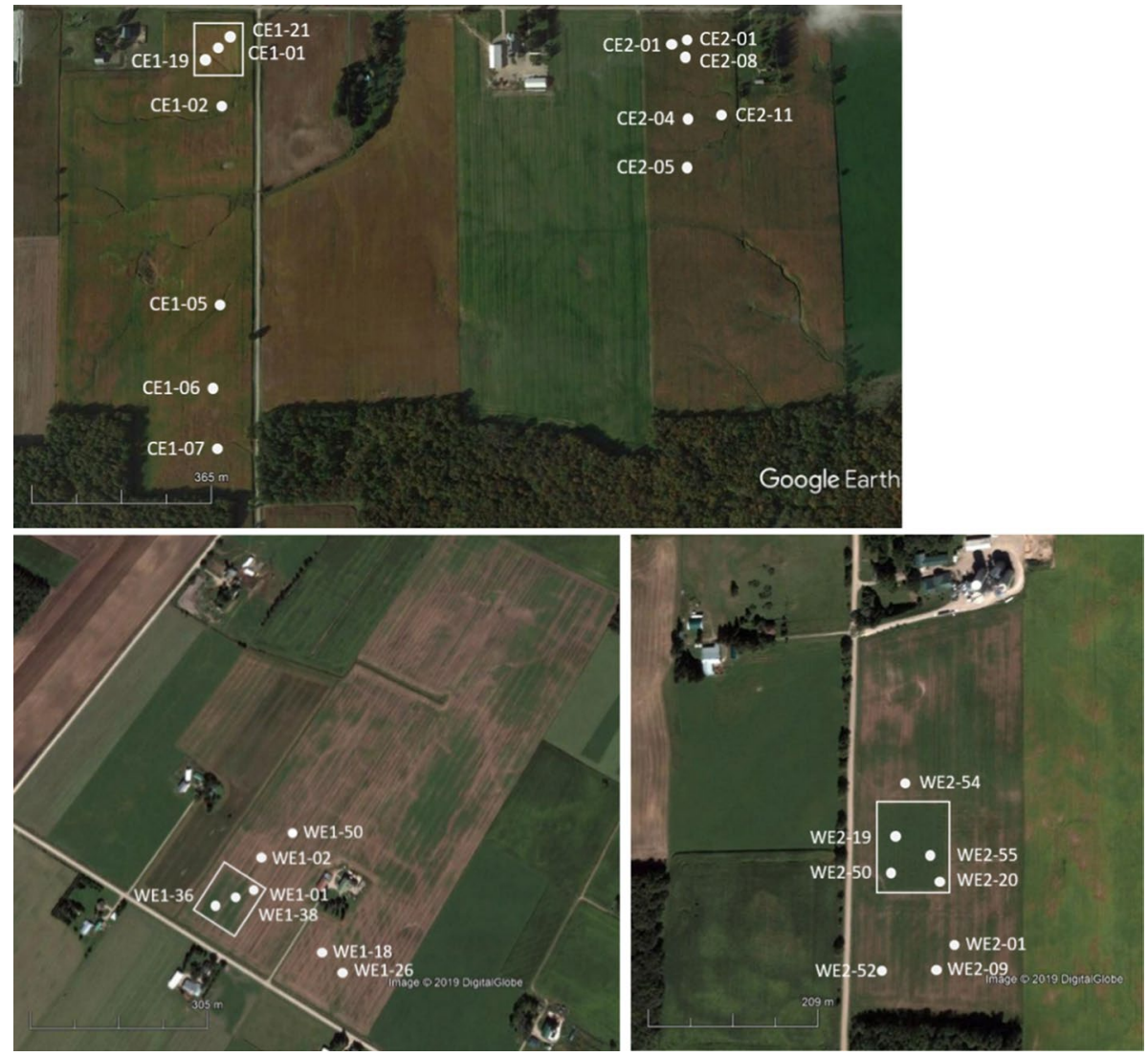

Fig. 1 No-nitrogen plots and field sampling sites shown with Google Earth images, for two corn fields (CE1 and CE2) in the first row, and two wheat fields (WE1 and WE2) in the second row. Background image is from Google Earth, (c) 2019 Digital Globe (Accessed 1st March, 2019)

leaves sampled from the top of the canopy, representing the maximum leaf chlorophyll potential for a given date (Zhang et al. 2007). Leaf reflectance and transmittance were measured using an Analytical Spectral Devices (ASD) Fieldspec Pro FR spectroradiometer (350-2500 nm; Analytical Spectral Devices Inc., Boulder, CO, USA) attached to a LI-COR 1800 integrating sphere (LI-COR, Lincoln, NE, USA), which provides an angular integration of radiant flux to give a uniform optical measurement. The ASD spectroradiometer was turned on for 90 min prior to sampling to allow the device to warm up. A dark measurement was taken before each sampling of leaf reflectance to remove the influence of electrical noise. A leaf was placed in the sample port of the integrating sphere and the reflectance spectrum $\left(R_{\lambda}\right)$ of each leaf was calculated as:

$$
R_{\lambda}=\frac{\text { Leaf radiance }{ }_{\lambda}}{\text { Calibration panel radiance }}
$$

Leaf area index (LAI) was measured at the same sampling locations on the same days as leaf sampling, using the LI-2000 plant canopy analyser (LI-COR, Lincoln, NE, USA), 
following the methods outlined by Chen et al. (1997). Measurements were taken in uniform sky conditions and diffuse irradiance conditions. A $90^{\circ}$ view cap was used to mask the operator from the instrument. Two reference measurements at the beginning of each measurement sequence were taken above the canopy in an open area at each site. After the reference was taken, nine below canopy measurements were taken perpendicular to the row direction at each sampling location.

\section{Satellite data}

Landsat-8 Surface Reflectance data (30 $\mathrm{m}$ spatial resolution, 16 day revisit time) were downloaded from Earth Explorer (http://earthexplorer.usgs.gov, accessed June, 2015). The Landsat- 8 images were atmospherically and geometrically corrected by the USGS using the $6 \mathrm{~S}$ model and are ready for user application. Table 2 provides the dates available from Landsat- 8 in addition to the field dates of data collection to be compared. The solar zenith (defined as the angle between the zenith and the centre of the Sun's disc; $\theta s$ ) and the solar azimuth (defined as the angle from due north in a clockwise direction; $\varphi s$ ) at the time of image acquisition are also given. Landsat-8 (OLI) is fixed for nadir view and the view zenith angle (defined as the angle between the zenith and the sensor) is $<7.5^{\circ}$, and the influence of its variation across the scene on canopy radiative transfer modeling is assumed to be negligible.

\section{Deriving satellite leaf area index estimates}

LAI is a key input to physically-based leaf chlorophyll inversion algorithms (Croft et al., in press), as leaf chlorophyll and LAI are the dominant variables that affect canopy reflectance (Zhang et al. 2008). In order to retrieve leaf chlorophyll content, spatially-continuous inputs of LAI values must therefore be derived. The biomass-sensitive Reduced Simple Ratio (RSR, Chen et al. 2002) vegetation index (Eq. 2) was calculated for all corn and wheat sampling sites for all the valid Landsat-8 dates (Table 2).

Table 2 Summary of Landsat imagery, and the dates of field data collection

\begin{tabular}{llll}
\hline Field collection date & $\begin{array}{l}\text { Landsat-8 (OLI) } \\
\text { acquisition date }\end{array}$ & $\theta s$ & $\varphi s$ \\
\hline May 24 & - & - & - \\
June 5 & June 4 & 25.49 & 137.70 \\
June 18 & June 20 & 25.12 & 135.04 \\
June 26 & - & - & - \\
July 11 & July 15 & 27.35 & 135.68 \\
July 22 & - & - & - \\
August 7 & - & - & - \\
August 16 & August 16 & 34.00 & 144.08 \\
September 5 & September 8 & 40.20 & 151.80 \\
September 19 & September 17 & 43.78 & 154.60 \\
September 29 & September 24 & 49.19 & 156.58 \\
\hline
\end{tabular}

The solar zenith $(\theta s)$ and solar azimuth $(\varphi s)$ are also given 


$$
R S R=\frac{R_{\text {NIR }}}{R_{R}}\left(1-\frac{R_{\text {SWIR }}-R_{\text {SWIRmin }}}{R_{\text {SWIRmax }}-R_{\text {SWIRmin }}}\right)
$$

where $R_{\text {NIR }}, R_{R}$, and $R_{\text {SWIR }}$ are the reflectance in the near infrared (NIR), red, and shortwave infrared (SWIR) respectively. $R_{\text {SWIRmin }}$ and $R_{\text {SWIRmax }}$ are the minimum and maximum SWIR reflectance found in the image. These are found from the $1 \%$ boundary in the cumulative histogram of the SWIR band. According to Chen et al. (2002), RSR is more advantageous than the Simple Ratio (SR) for estimating leaf area index (LAI) because it helps improve the accuracy of LAI retrieval for mixed land cover types, and the background influence is suppressed with the use of the SWIR band. The SWIR band is sensitive to canopy water content (Chen et al. 2002). Importantly, the inclusion of an additional SWIR reflectance band to the chlorophyll inversion algorithm brings in independent structural information about the vegetation canopy. The field measured LAI and RSR-modelled LAI values are shown in Fig. 2.

Using the relationship between RSR and measured LAI, the following equation (Eq. 3) was used to derive spatially-continuous LAI values from the Landsat-8 images for input into the leaf chlorophyll inversion ("Methods" section).

$$
L A I=\frac{R S R+0.564}{4.10}
$$

\section{Modelling chlorophyll content using spectral vegetation indices}

Spectral vegetation indices are a quick and straightforward method of estimating leaf chlorophyll content (Croft et al. 2014; le Maire et al. 2008) for a range of different vegetation types. Typically, empirical relationships are developed between measured chlorophyll content and spectral reflectance from different combinations of wavebands. Vegetation indices offer advantages in that they require little expertise, minimal software knowledge, and are computationally fast. Airborne or satellite imagery that include a narrow red-edge band

Fig. 2 Relationship between field measured LAI and satellitederived RSR, for all wheat and corn sampling sites and cloudfree Landsat TM images throughout the 2013 growing season

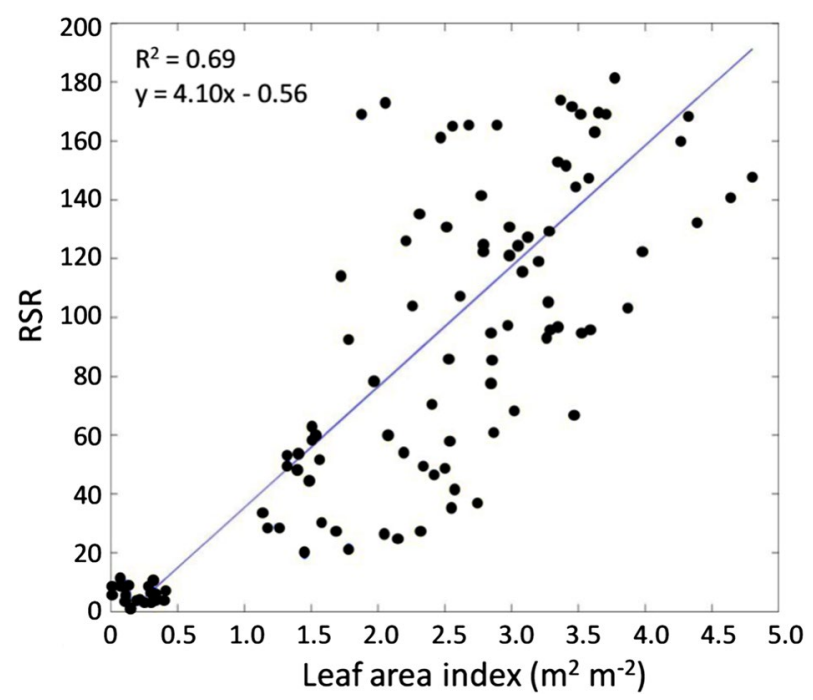


Table 3 A list of tested spectral indices in this study

\begin{tabular}{|c|c|c|c|}
\hline Index & Name & Formula & References \\
\hline BGI & Blue green pigment index & $R_{B} / R_{G}$ & Zarco-Tejada et al. (2005) \\
\hline $\mathrm{BI}$ & Brightness index & $\frac{R_{N I R}+R_{R}+R_{G}}{\sqrt{3}}$ & Liu and Moore (1990) \\
\hline DVI & Difference vegetation index & $R_{N I R}-R_{R}$ & Jordan (1969) \\
\hline EVI & Two band enhanced vegetation index & $\frac{2.5\left(R_{N I R}-R_{R}\right)}{R_{N I R}+2.42 R_{R}+1}$ & Jiang et al. (2008) \\
\hline G & Greenness index & $R_{\mathrm{G}} / R_{R}$ & Zarco-Tejada et al. (2005) \\
\hline GNDVI & Green NDVI & $R_{N I R}-R_{G} / R_{N I R}+R_{G}$ & Smith et al. (1995) \\
\hline GRg & Gitelson ratio green & $R_{N I R} / R_{G}-1$ & Gitelson et al. (2003) \\
\hline MCARI1 & Modified chlorophyll absorption 1 & $\begin{array}{l}1.2\left[2.5\left(R_{N I R}-R_{R}\right)\right. \\
\left.\quad-1.3\left(R_{N I R}-R_{G}\right)\right]\end{array}$ & Haboudane et al. (2004) \\
\hline NDVI & Normalized difference vegetation index & $R_{N I R}-R_{R} / R_{N I R}+R_{R}$ & Rouse et al. (1973) \\
\hline NPCI & Normalized pigment chlorophyll index & $R_{N I R}-R_{C} / R_{N I R}+R_{C}$ & Penuelas et al. (1995) \\
\hline OSAVI & Optimized soil-adjusted vegetation index & $\frac{1.16\left(R_{N I R}-R_{R}\right)}{R_{N I R}+R_{R}+0.16}$ & Rondeaux et al. (1996) \\
\hline RNDVI & $\begin{array}{l}\text { Renormalized difference vegetation } \\
\text { index }\end{array}$ & $R_{N I R}-R_{C} / \sqrt{R_{N I R}+R_{C}}$ & Roujean and Breon (1995) \\
\hline SAVI & Soil-adjusted vegetation index & $\frac{1.5\left(R_{N I R}-R_{R}\right)}{R_{N I R}+R_{B}+0.5}$ & Huete (1988) \\
\hline SIPI & Structure intensive pigment index & $R_{N I R}-R_{B} / R_{N I R}+R_{R}$ & Penuelas et al. (1995) \\
\hline SR & Simple ratio & $R_{N I R} / R_{R}$ & Jordan (1969) \\
\hline SPRI & Simple ratio pigment index & $R_{C} / R_{R}$ & Penuelas et al. (1995) \\
\hline
\end{tabular}

The formulae contains calculations using Landsat-8 OLI bands. $R_{C}=435-451 \mathrm{~nm}, R_{B}=452-512 \mathrm{~nm}$, $R_{G}=533-590 \mathrm{~nm}, R_{R}=636-673 \mathrm{~nm}, R_{N I R}=851-879 \mathrm{~nm}$

have proven to show strong linear correlations with chlorophyll measurements (Haboudane et al. 2002). However, relatively few studies have investigated the use of Landsat data for modelling leaf chlorophyll, due to its coarse spectral resolution and the lack of a red-edge spectral band. A total of 16 spectral vegetation indices were used in this study to test the accuracy by which leaf chlorophyll can be modelled using vegetation indices from multispectral data (Table 3).

\section{Chlorophyll-inversion modelling algorithm}

\section{Overview}

To derive leaf chlorophyll content from Landsat-8 reflectance data using a physically-based method, a two-step inversion approach similar to that of Zhang et al. (2008) was adopted. In the forward mode, radiative transfer models simulate leaf or canopy reflectance according to defined vegetation structural and biochemical variables that affect how light interacts with the canopy. The inverse mode (or model inversion) therefore estimates vegetation structural or biochemical variables from the leaf or canopy reflectance that is measured by a satellite sensor or field spectrometer, using the same radiative transfer model. The first step is the retrieval of leaf-level spectral reflectance from satellite-derived canopy reflectance data, using the SAIL radiative transfer model (Verhoef 1984) to account for the influence of canopy architecture, image acquisition conditions and background on canopy reflectance. To invert the SAIL model, a look up table (LUT) was created, based on 
variable and fixed input parameters. The LUT approach was selected to optimise computational resources and reduce problems associated with appearances of local minima, given sufficient sampling of the variable space (Jacquemoud et al. 2009). Whilst these structural parameterisations are important, their influence on canopy reflectance is mediated by LAI, which is the dominant driver of modelled canopy reflectance (Zhang et al. 2008).

The second step was to retrieve leaf chlorophyll content from the modelled leaf reflectance derived in Step 1, using the PROSPECT leaf optical model. A two-step inversion method is favoured over a coupled one-step inversion because the output of each stage can be assessed individually, and may be validated against measured leaf-level reflectance data at field sites (Croft et al. 2013; Zhang et al. 2008). This physically-based canopy inversion method has been successfully demonstrated previously using different combinations of canopy and leaf models (Croft et al. 2013; Moorthy et al. 2008; Zarco-Tejada et al. 2004; Kempeneers et al. 2008). A schematic overview of the chlorophyll-inversion algorithm is presented in Fig. 3.

\section{Step 1: canopy-level reflectance inversion using the SAIL model}

For the first step, the SAIL canopy reflectance model (Verhoef 1984) was selected, as agricultural crops can be treated as one-dimensional (1D) turbid media, i.e. randomly distributed absorbing and scattering elements. The SAIL model is one of the first canopy reflectance models and is based on Suits model which is founded on a set of four differential equations: (1) diffuse incoming flux (2) diffuse outgoing flux (3) direct solar flux, and (4) flux with radiance in the direction of remote sensing observation (Suits 1971). Table 4 presents the fixed and variable parameters used in the SAIL model. LAI is a

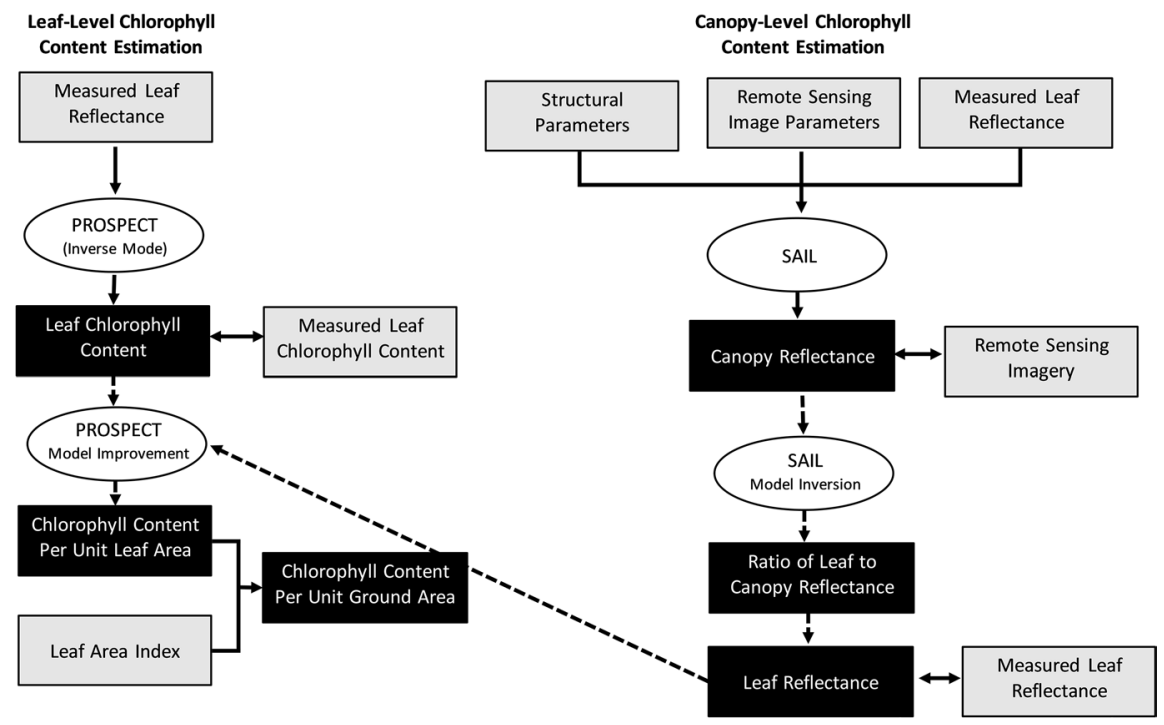

Fig. 3 Schematic overview of the two-step model inversion. The grey boxes represent inputs while the black boxes represent outputs. The dashed lines represent the inversion process and the double arrows present an opportunity to validate with empirical data. Modified from Zhang et al. (2008) 
Table 4 Fixed and variable parameters used in the SAIL model for LUT generation

\begin{tabular}{lllll}
\hline Symbol & Quantity & Units & Set value & $\begin{array}{l}\text { Increment- } \\
\text { ing step } \\
\text { factor }\end{array}$ \\
\hline LAI & Leaf area index & $\mathrm{m}^{2} \mathrm{~m}^{-2}$ & - & 0.1 \\
LIDF & Leaf inclination distribution function & - & Planophile & \\
SL & Hot spot parameter & $\mathrm{m} \mathrm{m}^{-1}$ & 0.5 & 10 \\
$\rho s$ & Soil reflectance factor (0 is wet and 1 is dry) & - & 0 & - \\
$\theta s$ & Solar zenith angle & $\circ$ & $0^{\circ}$ & \\
$\theta$ & View zenith angle & $\circ$ & $0^{\circ}$ & \\
$\varphi s$ & Relative azimuth angle & $\circ$ & & \\
\hline
\end{tabular}

Two LUTs were created with the same parameters but with different inputs of leaf reflectance; one healthy and one unhealthy leaf

variable parameter and is input according to the RSR-modelled retrieval ("Deriving satellite leaf area index estimates" section), incrementing at 0.1 steps in the LUT, from a minimum value of 0.1 to a maximum value of 10 . The solar zenith angle was set to increment between $0^{\circ}$ and $60^{\circ}$ with increments of $10^{\circ}$ and is retrievable from the Landsat- 8 acquisition metadata. The soil factor was set to 0 , equivalent to a wet soil. This is likely to be the case in the early part of the growing season during spring months that experience more rainfall. During the summer, the LAI is higher and very little background soil will be visible, so any deviation from real conditions will have a negligible impact on the canopy reflectance inversion, due to its low contribution to canopy reflectance. The hotspot parameter quantifies the ratio between leaf size and canopy height (Jacquemoud et al. 1995), and falls between the values of $0-1$ (Jacquemoud et al. 1995). This parameter has negligible effects on simulated canopy reflectance under Landsat acquisition conditions, because the vegetation canopy is observed far from the hotspot. The hotspot was set to a constant value of 0.5 , based on estimates of plant height relative to leaf size (Vincini and Frazzi 2011).

The leaf inclination distribution function (LIDF) describes the frequency distribution of leaf orientation angles irrespective of azimuthal distribution, using terminology introduced by de Wit (1965). The same crop can be architecturally different according to the cultivar and genetic differences, stem density, leaf size and growth stage. Winter wheat is commonly classified as erectophile (angular distribution of leaves is predominately vertical) or planophile (angular distribution of leaves is predominately horizontal) (Yanli et al. 2007; Huang et al. 2006; Jackson and Pinter Jr. 1986). Hosoi and Omasa (2009) found that during the stem elongation and flowering stages, most leaves bent downwards to horizontal positions (i.e. planophile distribution). The angular distribution of corn leaves has been considered planophile, erectophile or spherical (the angular distribution of leaves is the same as the surface elements of a sphere) (Wang et al. 1995; Jacquemoud et al. 2000; Nguy-Robertson et al. 2012; Fang 2015). Based on visual inspection in the field, both corn and wheat in this study could be considered as planophile, meaning that leaves are more horizontal than the spherical distribution (Du et al. 2017; Fang 2015; Hosoi and Omasa 2009), with the majority of leaves approaching horizonal orientation (Fig. 4), although some young corn leaves showed a tendency of vertical orientation.

Using the same model parameterisation for both crop types will also offer an opportunity to assess the transferability of the algorithm across crop types; limiting the need 
(a)

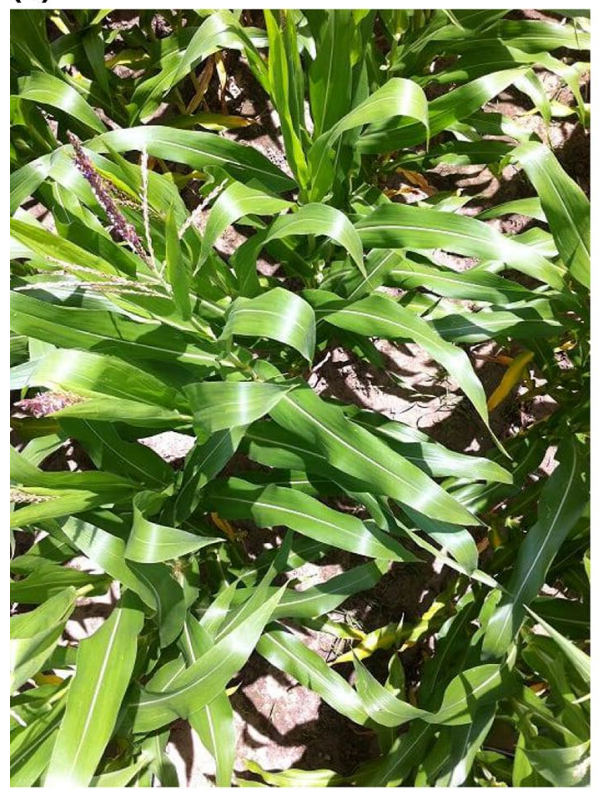

(b)

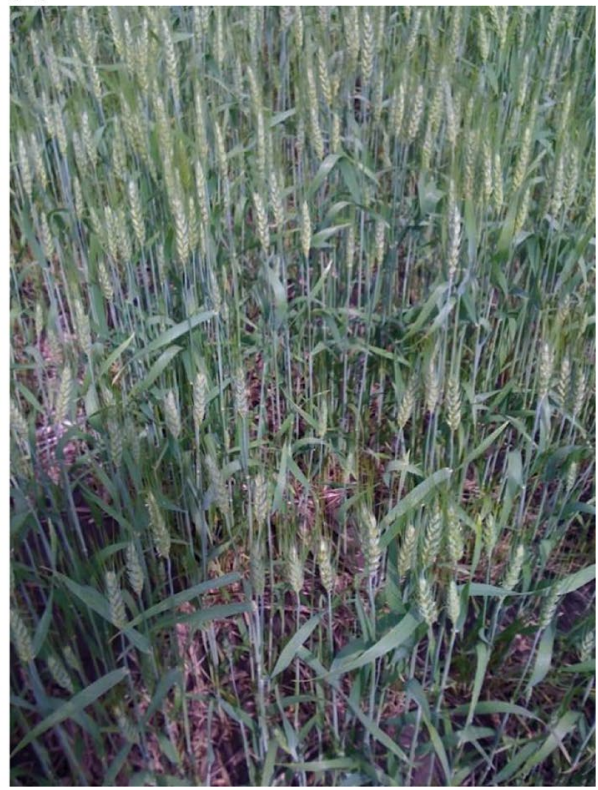

Fig. 4 Photographs of representative (a) corn, (b) wheat sites

for local information, such as species type. Whilst setting the LiDF to planophile for both species throughout the growing season may lead to some uncertainty in modelled chlorophyll prediction, Vincini et al. (2016) demonstrated that with the exception of erectophile LIDFs, varying the LIDF had relatively small impacts on the strength of the relationship between chlorophyll and spectral indices, particularly when the solar zenith angle is between $30^{\circ}-60^{\circ}$. This was also confirmed by (Croft et al., in press), where the imposed error on leaf chlorophyll prediction using physical-based inversion methods was quite consistent between spherical, planophile, plagiophile (where oblique leaves are most frequent) and uniform canopies, with only erectophile canopies presenting a large difference. In this sensitivity analysis, it was also found that for a fully expanded canopy $(\mathrm{LAI}=4.0)$, deviations in the hotspot parameter value from the assigned value by $100 \%$, only resulted in a negligible change $\left(-1.2 \mu \mathrm{g} \mathrm{cm}^{-2}\right)$ in modelled leaf chlorophyll content values (Croft et al., in press). The inclusion of LAI as a variable parameter mediates against much of the uncertainty generated in fixed structural parameters.

Two separate LUTs were created, using leaf-level reflectance data from a nitrogen deficit ('unhealthy') leaf, and a fertilised ('healthy') leaf into SAIL, to forward model canopy reflectance of an unhealthy crop and a healthy crop. The LUT contained the ratio between the input leaf reflectance into SAIL, and the output modelled canopy reflectance (see Eq. 4), as a 'scaling factor', which encompassed the signal from soil reflectance, bidirectional reflectance distribution function (BRDF) effects and multiple scattering within the canopy, according to the structural parameterisations detailed in Table 4. Accordingly, the leaf level reflectance for each Landsat-8 pixel was found by multiplying the pixel's canopy reflectance by the Scalingfactor $_{(\lambda)}$ according to the pixel specific LAI value and solar/viewing angle value within the LUT. 


$$
\text { Scaling factor }_{(\lambda)}=\frac{R_{\text {Leaf }(\lambda)}}{R_{\text {Canopy }(\lambda)}}
$$

\section{LUT inversion through inverse distance weighting}

The leaf reflectance input for SAIL greatly influences the output of modelled canopy reflectance. Using a 'healthy' leaf reflectance to forward-model canopy reflectance in order to generate the LUT may bias the leaf-level inversion for the leaves experiencing stress. In order to compensate for this potential bias, healthy and unhealthy leaf LUTs were created and inverse distance weighting was applied pixel by pixel for the best match. Each pixel in the Landsat- 8 image was compared with the two LUTs (healthy and unhealthy) to find the Scalingfactor $_{(\lambda)}$ value according to the pixel's solar zenith angle and LAI conditions. An inverse distance weighting (IDW) was applied to extrapolate an appropriate ratio value between the healthy and unhealthy LUT match. IDW is based on the concept that nearer points are more similar than further points. By this theory, if a Landsat pixel's canopy reflectance was more similar to the forward modelled canopy reflectance using the unhealthy leaf reflectance, it would apply a greater influence to the Scalingfactor $_{(\lambda)}$ values that would be used to calculate leaf reflectance. The canopy reflectance from the Landsat- 8 scene was compared to the LUT healthy and unhealthy match. Based on the distance (or difference) between the healthy and unhealthy and the Landsat- 8 image, a weighting was applied on the ratio. Equation 5 gives the IDW equation used to calculate the $\operatorname{Ratio}_{(\lambda)}$ that was used in each individual pixel's case:

$$
\operatorname{Ratio}(\lambda)=\frac{\left(\frac{\text { Ratio }_{\text {healthy }}(\lambda)}{d_{\text {healthy }}}+\frac{\text { Ratio }_{\text {unheealthy }}(\lambda)}{d_{\text {unhealthy }}}\right)}{\left(\frac{1}{d_{\text {healthy }}}+\frac{1}{d_{\text {unhealthy }}}\right)}
$$

where $\operatorname{Ratio}_{(\lambda)}$ is the ratio found for the particular pixel, Ratiohealthy $(\lambda)$ and Ratiounhealthy $_{(\lambda)}$ are the ratios found from the match in the healthy and unhealthy LUT respectively, and

$$
\begin{gathered}
d_{\text {healthy }}=\left[\text { Modelled Ref } f_{\text {healthy }(\lambda)}-\text { Landsat } \operatorname{Re} f_{(\lambda)}\right]^{2} \\
d_{\text {unhealthy }}=\left[\text { Modelled Ref } f_{\text {unhealthy }(\lambda)}-\text { Landsat } \operatorname{Re} f_{(\lambda)}\right]^{2}
\end{gathered}
$$

\section{Leaf-level chlorophyll retrieval using the PROSPECT model}

The leaf radiative transfer model PROSPECT (Jacquemoud and Baret 1990; Feret et al. 2008) was then used to derive leaf chlorophyll content from the modelled leaf reflectance spectra generated in step one ("Modelling chlorophyll content using spectral vegetation indices" section). In PROSPECT-5, leaf reflectance and transmittance (400-2500 nm) are defined as a function of six parameters: structure parameter $(\mathrm{N})$, chlorophyll $(\mathrm{a}+\mathrm{b})$ concentration $\left(\mathrm{C}_{\mathrm{ab}}\right)$, brown pigment $\left(\mathrm{C}_{\mathrm{b}}\right)$, dry matter $\left(\mathrm{C}_{\mathrm{m}}\right)$ and equivalent water thickness $\left(\mathrm{C}_{\mathrm{w}}\right)$. Absorption is calculated as the linear summation of the specific absorption coefficients of the biochemical constituents and their respective concentrations (Feret et al. 2008). 
PROSPECT has been widely tested across a large number of vegetation species and plant functional types, and is popular because of its accuracy and straightforward inversion, due to the relatively few leaf parameters within the model (Croft et al. 2015; Demarez and Gastellu-Etchegorry 2000; Darvishzadeh et al. 2008; Malenovský et al. 2006). The PROSPECT model is inverted to model leaf chlorophyll content from input leaf reflectance by iteratively minimising a merit function (Feret et al. 2008).

\section{Landsat data simulation and hyperspectral spectral comparison}

To investigate the impact of using Landsat- 8 spectral bands instead of hyperspectral reflectance on PROSPECT-modelled leaf chlorophyll content, Landsat- 8 bands were simulated from wheat and corn hyperspectral leaf reflectance for all sampling dates and sites ("Field data collection" section). The Landsat-8 reflectance was simulated using the sensor's spectral response function (SRF), which describes its relative sensitivity to different wavelengths, and the measured leaf hyperspectral data (Eq. 8).

$$
L=\frac{\sum_{\lambda=1}^{N} \beta(\lambda) L^{\prime}(\lambda)}{\sum_{\lambda=1}^{N} \beta(\lambda)}
$$

In the weighted sum formula above, $L$ is the broadband Landsat- 8 reflectance and $L^{\prime}(\lambda)$ is the original hyperspectral reflectance. $(\lambda)$ is weight of the broadband Landsat- 8 spectral response function (Chen et al. 2002). The PROSPECT absorption coefficients were also recalculated to the Landsat-8 spectral resolution using their respective spectral response functions. By inverting PROSPECT using Landsat- 8 simulated bands, the accuracy of the modelled leaf chlorophyll, using both hyperspectral and broadband reflectance inputs, could be directly compared.

\section{Results}

\section{Seasonal trends of LAI and leaf chlorophyll content}

The temporal trends in measured leaf chlorophyll and LAI through the growing season are shown in Fig. 5, for the fertilized (N) and non-fertilized (Zero N) sites in the four fields. Winter wheat commences growth earlier (DOY 130), following seeding during the previous winter. Mid-season maximum values were reached around DOY 170 for LAI and DOY 155 for leaf chlorophyll. The last measurement before harvest was on DOY 200, when LAI remained reasonably high $(\mathrm{N} L A I=\sim 3.0$, Zero-N LAI $=\sim 1.0)$, whilst chlorophyll had declined to $<20 \mu \mathrm{g} \mathrm{cm}^{-2}$. The corn crops began growing at DOY 160 , reaching maximum LAI and chlorophyll values at DOY $\sim 200$, and declined slowly toward the later season.

The application of nitrogen fertiliser had a considerable impact on peak values of both LAI and chlorophyll in the middle of the growing season. For wheat, the fertilized fields had a maximum average LAI of 4.3, while the non-fertilized fields only reached a maximum average LAI of 1.6. Fertilizer application appeared to have a smaller impact on the LAI of maize, although CE1 Zero-N values were still lower than the sites that received nitrogen. Changes in leaf chlorophyll content across the growing season also show differences between nitrogen and no-nitrogen application areas, with fertilized sites reaching a higher value of leaf chlorophyll content than non-fertilized areas. For wheat, the maximum 
(a)

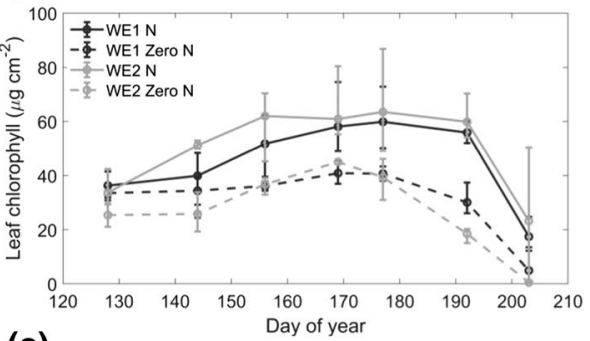

(c)

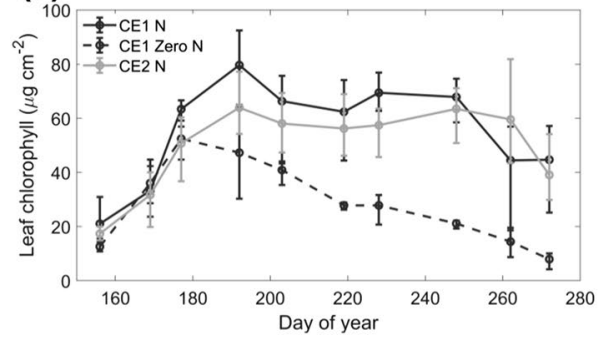

(b)

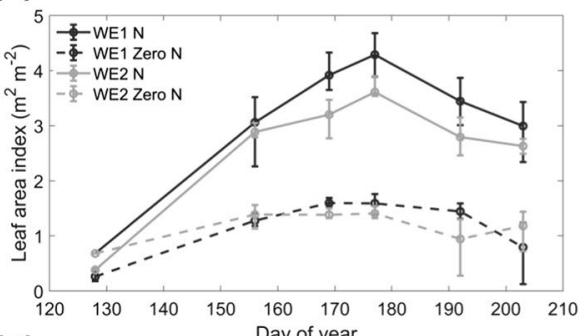

(d)

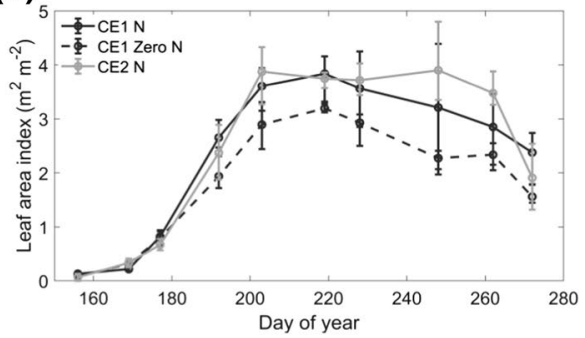

Fig. 5 Temporal variations in mean leaf chlorophyll for (a) wheat, (c) corn, and in mean LAI for (b) wheat, (d) corn, throughout the growing season. The error bars represent the minimum and maximum values for each field, and nitrogen fertiliser application is indicated by $\mathrm{N} /$ Zero $\mathrm{N}$

chlorophyll content is $64 \mu \mathrm{g} \mathrm{cm} \mathrm{cm}^{-2}$ in fertilized plots, while it is only $45 \mu \mathrm{g} \mathrm{cm} \mathrm{cm}^{-2}$ in nonfertilized plots. Nitrogen application also affects the chlorophyll content in maize and to a greater extent than it affects LAI values, with the maximum values of $80 \mu \mathrm{g} \mathrm{cm}^{-2}$ and $47 \mu \mathrm{g} \mathrm{cm}^{-2}$ for $\mathrm{N}$ and Zero-N sites, respectively. Additionally, leaf chlorophyll in no nitrogen application areas started to decline even in the growth period in the middle of the growing season, much earlier than their corresponding nitrogen fertilised sites.

\section{Estimating crop chlorophyll with spectral vegetation indices}

The performance of a number of spectral vegetation indices are evaluated for modelling leaf chlorophyll content using Landsat-8 reflectance data (Table 5). The applicability of these indices for monitoring fine-scale $(30 \mathrm{~m})$ variations in chlorophyll content at the subfield scale is important for operational agricultural applications.

The best performing indices for corn were GNDVI, GRg, EVI and SAVI with $\mathrm{R}^{2}$ values of $0.67,0.60,0.56$, and 0.56 respectively. For wheat, many of the indices had similar $\mathrm{R}^{2}$ values to corn, ranging between 0.32 and 0.54 . However, like corn, GRg, SAVI, EVI and GNDVI were amongst the top performing indices with $\mathrm{R}^{2}$ of $0.54,0.49,0.49$, and 0.48 , respectively. When combining the two crops types, GNDVI presented the strongest correlation $\left(\mathrm{R}^{2}=0.59\right)$. Regressions for the best performing indices for each crop type, and both combined are presented in Fig. 6.

The results for both crop types combined (Fig. 6c) indicate that there is a degree of transferability in the selected GNDVI vegetaion index between the two crops, although the modelled leaf chlorophyll values for wheat would often be under-estimated based on this regression equation. The relationship between GNDVI and chlorophyll content has a 
Table 5 A summary of the results from spectral indices

\begin{tabular}{|c|c|c|c|c|c|c|}
\hline \multirow[t]{2}{*}{ Index } & \multicolumn{2}{|l|}{ Corn } & \multicolumn{2}{|l|}{ Wheat } & \multicolumn{2}{|c|}{ Corn and wheat } \\
\hline & $\mathrm{R}^{2}$ & Regression equation & $\mathrm{R}^{2}$ & Regression equation & $\mathrm{R}^{2}$ & Regression equation \\
\hline BGI & $0.21 * *$ & $187.90 x-33.00$ & $0.39 * *$ & $-127.94 x+114.18$ & 0.03 & $58.02 x+24.08$ \\
\hline $\mathrm{BI}$ & $0.20 * *$ & $21.39 x-10.70$ & $0.32 *$ & $26.49 x-13.63$ & $0.17 * *$ & $17.62 x+2.56$ \\
\hline DVI & $0.41^{* *}$ & $13.26 x+0.83$ & $0.45 * *$ & $10.68 x+18.27$ & $0.37 * *$ & $11.43 x+10.22$ \\
\hline EVI & $0.55^{* *}$ & $53.38 x-32.05$ & $0.49 * *$ & $29.78 x+8.17$ & $0.49 * *$ & $44.74 x-17.08$ \\
\hline G & $0.23 * *$ & $33.88 x-0.33$ & $0.40 * *$ & $27.29 x+12.71$ & $0.24 * *$ & $31.44 x+4.85$ \\
\hline GNDVI & $0.67 * *$ & $197.23 x-101.9$ & $0.48 * *$ & $97.71 x-22.43$ & $0.59 * *$ & $164.01 x-75.02$ \\
\hline GRg & $0.60 * *$ & $5.43 x+7.63$ & $0.54 * *$ & $3.48 x+26.66$ & $0.56 * *$ & $4.83 x+13.83$ \\
\hline MCARI1 & $0.38 * *$ & $8.39 x+3.45$ & $0.45^{* *}$ & $6.88 x+19.52$ & $0.34 * *$ & $7.27 x+12.19$ \\
\hline NDVI & $0.56^{* * *}$ & $150.63 x-73.71$ & $0.48 * *$ & $78.93 x-12.02$ & $0.50 * *$ & $125.33 x-51.73$ \\
\hline NPCI & $0.49 * *$ & $-129.39 x+93.67$ & $0.49 * *$ & $-338.20 x+152.19$ & $0.45^{* *}$ & $-130.9 x+92.99$ \\
\hline OSAVI & $0.55^{* *}$ & $129.01 x-68.59$ & $0.48 * *$ & $68.53 x+9.88$ & $0.50 * *$ & $107.47 x-47.45$ \\
\hline RNDVI & $0.42^{* *}$ & $1.72 x-52.30$ & $0.46 * *$ & $1.09 x-7.36$ & $0.34 * *$ & $1.34 x-26.98$ \\
\hline SAVI & $0.56 * *$ & $85.17 x-35.73$ & $0.49 * *$ & $46.12 x+6.99$ & $0.50 * *$ & $71.14 x+20.11$ \\
\hline SIPI & $0.49 * *$ & $-224.92 x+287.31$ & $0.44 * *$ & $-189.62 x+250.28$ & $0.48 * *$ & $-219.09 x+281.18$ \\
\hline SR & $0.48 * *$ & $2.25 x+19.41$ & $0.49 * *$ & $1.51 x+33.01$ & $0.46^{* *}$ & $2.02 x+23.95$ \\
\hline SPRI & $0.47 * *$ & $116.54 x-8.94$ & $0.48 * *$ & $281.09 x-100.79$ & $0.44 * *$ & $119.19 x-11.12$ \\
\hline
\end{tabular}

Relationships between the index and empirical chlorophyll measurements are displayed in the table. Linear regressions were used for analysis

$* \mathrm{p}<0.01, * * \mathrm{p}<0.001$

(a)

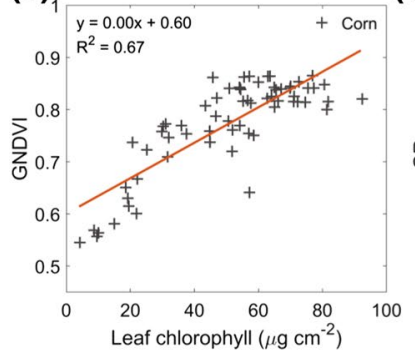

(b)

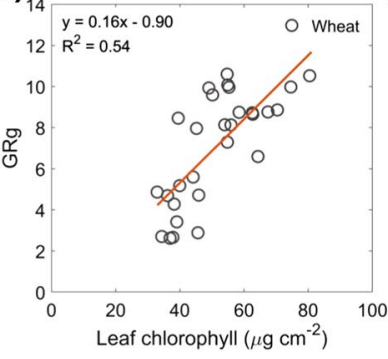

(c)

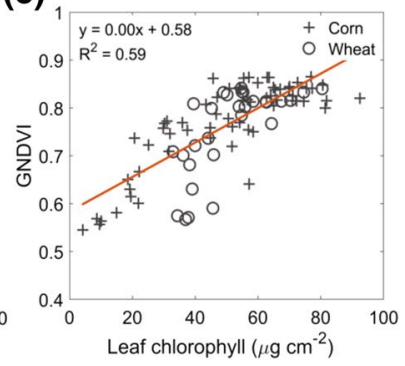

Fig. 6 The top performing spectral indices for (a) corn, (b) wheat, (c) both corn and wheat combined, against measured leaf chlorophyll content

curvilinear nature, indicating saturation at higher chlorophyll contents. This is a typical response of indices that are comprised of red band reflectance, which are prone to saturation (Croft and Chen 2018). 


\section{Physically-based chlorophyll modelling}

\section{Multispectral and hyperspectral PROSPECT inversion}

At the leaf level, PROSPECT is usually inverted with hyperspectral reflectance as input data. However, this is not possible for multispectral satellite-derived reflectance data, and precludes the use of a wealth of available satellite data for agricultural leaf chlorophyll determination. Before modelling leaf chlorophyll from the satellite Landsat-8 imagery, the implications of using a reduced bandset on the accuracy of PROSPECT chlorophyll estimates are first tested against hyperspectral reflectance inputs. The hyperspectral leaf reflectance data was used to simulate Landsat- 8 bands, using Landsat- 8 SRFs ("Modelling chlorophyll content using spectral vegetation indices" section), so results from the simulated Landsat- 8 bands and the hyperspectral data could be compared directly (Fig. 7).

Figure 7 reveals strong linear relationships between modelled and measured leaf chlorophyll, with a slightly stronger relationship for hyperspectral data. Overall, PROSPECT performed well for corn and wheat combined, with $\mathrm{R}^{2}=0.79$ for hyperspectral data and $\mathrm{R}^{2}=0.78$ for simulated Landsat- 8 data. These results suggest that at the leaf-level, PROSPECT is capable of estimating leaf chlorophyll using Landsat bands at accuracies comparable to those from hyperspectral inputs. However, PROSPECT under predicted chlorophyll values from both the hyperspectral and multispectral data, with the regression falling below the 1:1 line, particularly for wheat. When permitted to vary freely, the leaf structural parameter ( $\mathrm{N}$ parameter) ranged between 0.3 and 2.9. Other studies have suggested setting the $\mathrm{N}$ parameter to a mean of 2.0 (with a SD of 0.34 ) for winter wheat (Atzberger et al. 2003), or a wider range of 1.0-2.5 (Danner et al. 2017). Alternatively, Shiklomanov

(a)

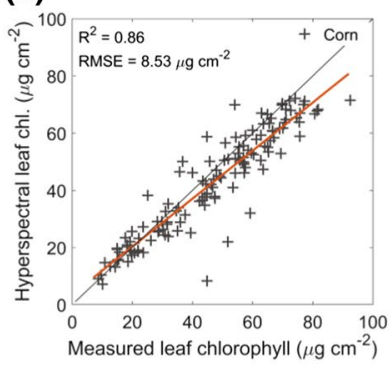

(d)

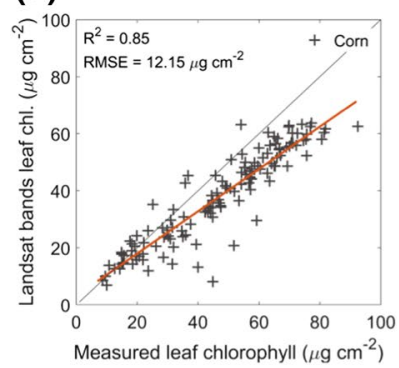

(b)

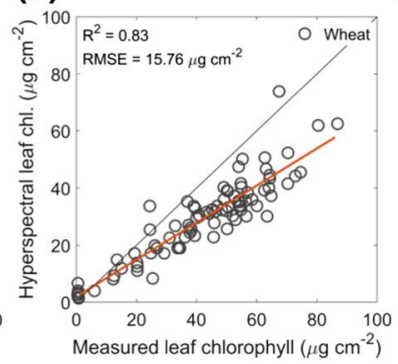

(e)

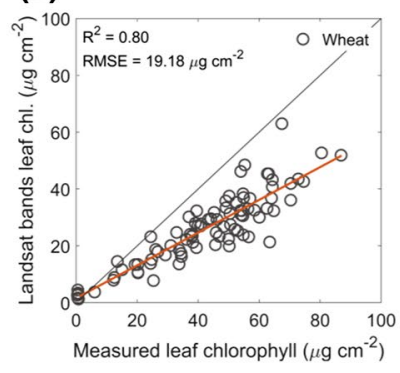

(c)

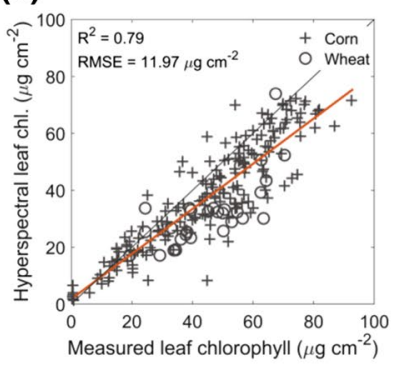

(f)

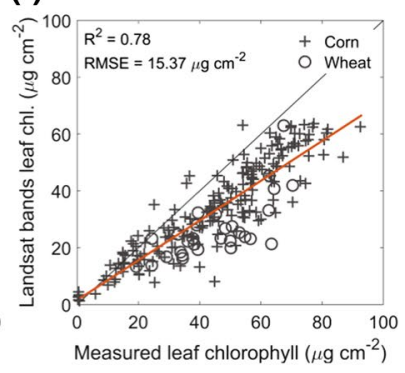

Fig. 7 Leaf chlorophyll content estimated from PROSPECT model inversion for wheat and corn, separately and in combination, using hyperspectral $(\mathbf{a}-\mathbf{c})$ and simulated Landsat bands $(\mathbf{d}-\mathbf{f})$ 
et al. (2016) suggests that a bias in modelled chlorophyll values could be due to a failure of PROSPECT-5 to accurately represent the spectral properties of chlorophyll in leaves, as the specific absorption feature for chlorophyll a and $b(\mathrm{kCab}(\lambda))$ in PROSPECT-5 is empirically calibrated from a the ANGERS dataset, which takes is name from the city of Angers, France, where it was measured in 2003 (Feret et al. 2008). This may lead to inaccurate inversion estimates, for species dissimilar to those in the ANGERS data set (Shiklomanov et al. 2016). To correct for a potential mis-representation of internal leaf structure on PROSPECT modelled reflectance the value of the $\mathrm{N}$ parameter was incrementally adjusted until the slope value was closest to 1 . The new results with the $\mathrm{N}$ parameter to set a value of 3 to correct for the systematic underestimation of leaf chlorophyll are presented in Fig. 8 .

Figure 8 demonstrates the improved performance of PROSPECT when the N parameter is set to 3 . Whilst the strength of the regression results remained fairly similar to the results where the $\mathrm{N}$ parameter was allowed to vary freely, specifying $\mathrm{N}=3$ improves the Landsat RMSE value from 13.62 to $9.45 \mu \mathrm{g} \mathrm{cm}^{-2}$, but worsens the hyperspectral RMSE from 11.97 to $15.37 \mu \mathrm{g} \mathrm{cm}^{-2}$ (Figs. 7c, f and 8). While $\mathrm{N}$ was set for this study, it is recognised that this may restrict the operational utility of the inverse modeling approach across different sites and species. Further research is needed to refine estimation of the $\mathrm{N}$ parameter. Further research directions could be to model the $\mathrm{N}$ parameter with leaf thickness and internal cellular structural information. Some approaches have relied on constraining the PROSPECT inversion to individual parameters based on different sensitive wavelengths ranges. Zarco-Tejada et al. (2004) used NIR wavelengths to first retrieve the N parameter, which was fixed accordingly per chlorophyll inversion. The limited number of wavebands in this multispectral study make this difficult.

\section{Modelling chlorophyll from Landsat satellite data}

Following the testing and optimising of the PROSPECT model at the leaf level, using leaf reflectance data, leaf and canopy chlorophyll content are now modelled using the two-step inversion approach directly from Landsat satellite data (Fig. 9).

The regression results indicate that the algorithm is performing quite well for satellite canopy reflectance inversions. The correlation between estimated and measured values for

(a)

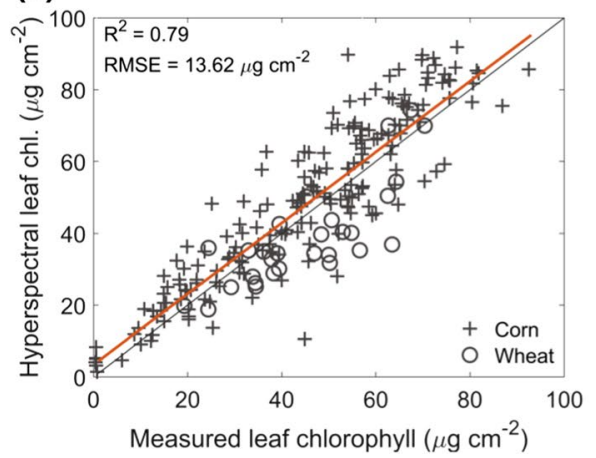

(b)

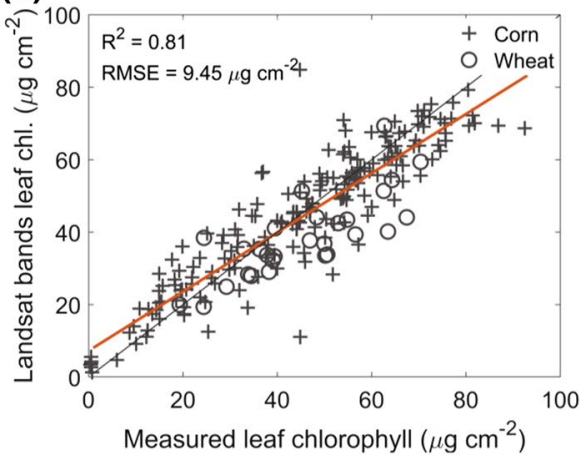

Fig. 8 PROSPECT chlorophyll estimates compared to measured chlorophyll, where $\mathrm{N}=3.0$ for (a) hyperspectral wavelengths, (b) simulated Landsat bands 
(a)

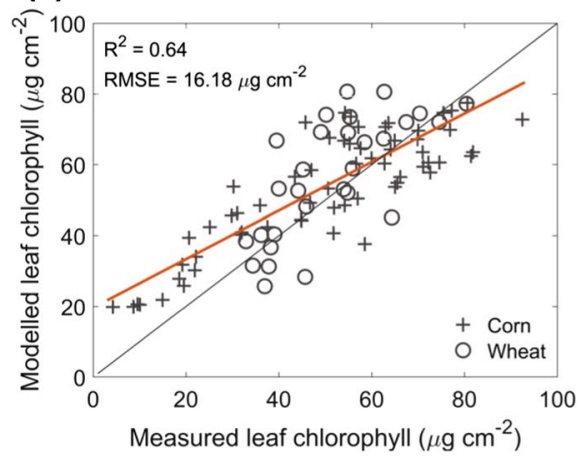

(b)

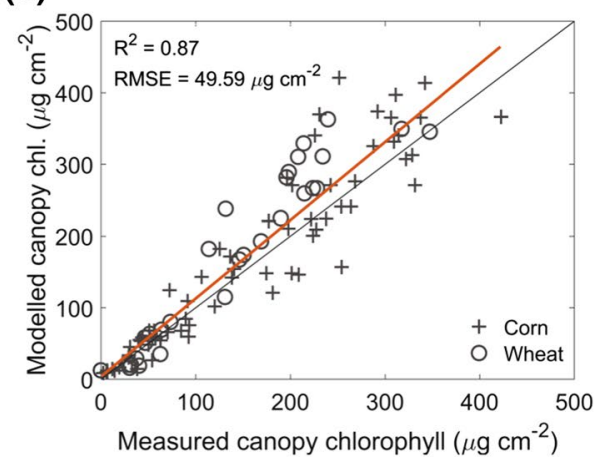

Fig. 9 Two-step inversion validation, for (a) leaf-level chlorophyll content and b canopy-level chlorophyll content

canopy chlorophyll content is particularly strong $\left(\mathrm{R}^{2}=0.87\right)$ because canopy chlorophyll is coupled with LAI. The modelled leaf level results are also good $\left(\mathrm{R}^{2}=0.64\right)$, with some overestimations for corn at lower chlorophyll values, which could be due to mis-parameterisation of LiDF at the start of the season where corn canopies may be more erectophile as young leaves tend to be clustered around the stalks (Monteith 1969).

The spatial variability in leaf chlorophyll content, derived from the Landsat images at select dates across the growing season, can be seen in Fig. 10. The no nitrogen application areas are highlighted by a black box labelled with "N/F".

The no nitrogen areas show clearly apparent lower leaf chlorophyll content values than the surrounding areas, however considerable spatial variation also exists even within the fertilised area (Fig. 10). While collection dates and available Landsat-8 imagery were limited for wheat plots, the corn plots had more cloud-free satellite data available, allowing seasonal trends to also be visible. The progression of images from July 15th to September 24th shows the change in chlorophyll content from the middle of the season to the end of the season for the corn fields, and the degree of variability in chlorophyll values that is present within a field on all dates through the season. The decline in chlorophyll content values are visible within this mapped time series, with the non-fertilized areas declining earlier than the fertilized areas.

\section{Discussion}

\section{Multispectral reflectance data can be used to accurately model leaf chlorophyll content}

To date, the integration of multispectral satellite sensors in leaf chlorophyll or nitrogen monitoring studies has been relatively low. In an early study, Jacquemoud et al. (1995) tested the use of Airborne Visible/Infrared Imaging Spectrometer (AVIRIS) hyperspectral data and Landsat TM bands within the PROSAIL model for modelling sugar beet biochemical properties, finding similar results for both input datasets. Croft et al. (2015) also found similar results for hyperspectral reflectance data and simulated Landsat bands for needleleaf and broadleaf samples, using PROSPECT-5 $\left(\mathrm{R}^{2}=0.76\right.$ and $\mathrm{R}^{2}=0.79$, respectively). This study confirms 
(a)

\section{CE1 \& CE2 - July 15th 2013}

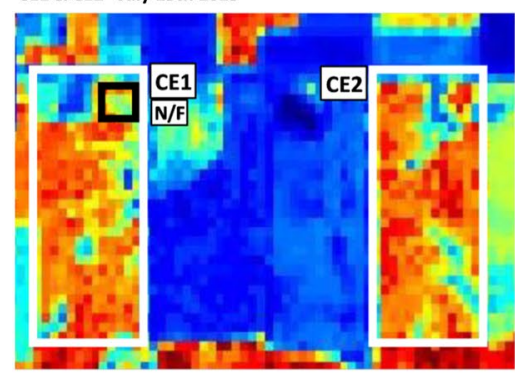

CE1 \& CE2 - September 8th 2013

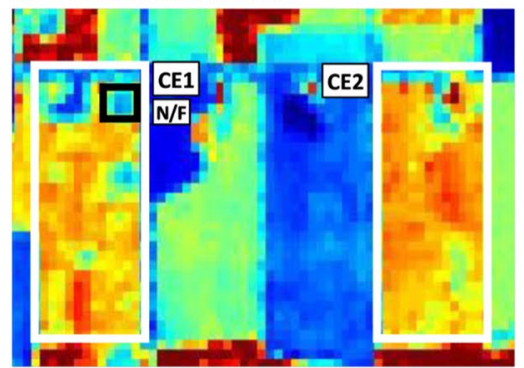

CE1 \& CE2 - September 17th 2013

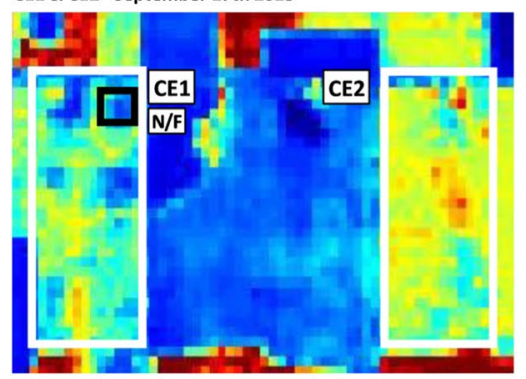

CE1 \& CE2 - September 24th 2013

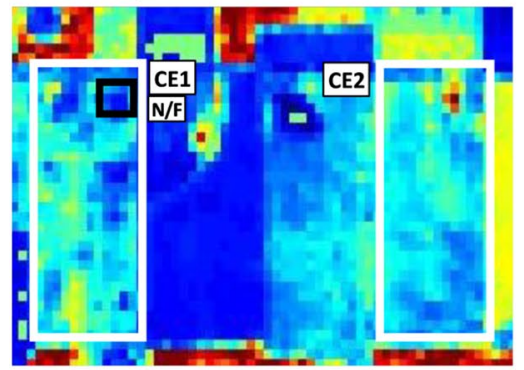

$0 \quad 210 \quad 420 \mathrm{~m}$ (b)

$\mathrm{Chl}\left(\mu \mathrm{g} \mathrm{cm}^{-2}\right)$

WE1 - June 5th 2013

$\mathrm{Chl}\left(\mu \mathrm{g} \mathrm{cm}^{-2}\right)$

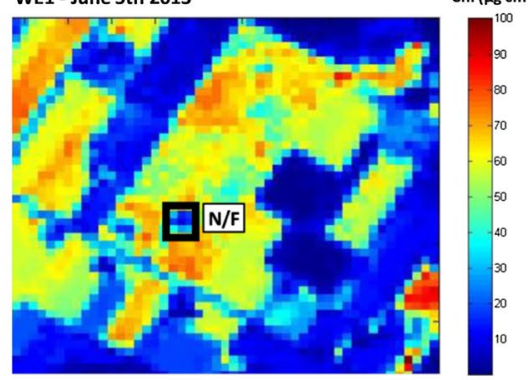

WE1 - June 18th 2013

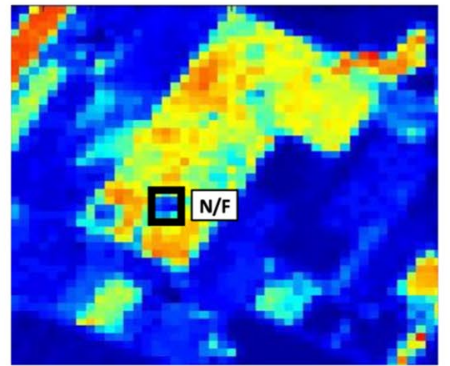

WE2 - June 5th 2013

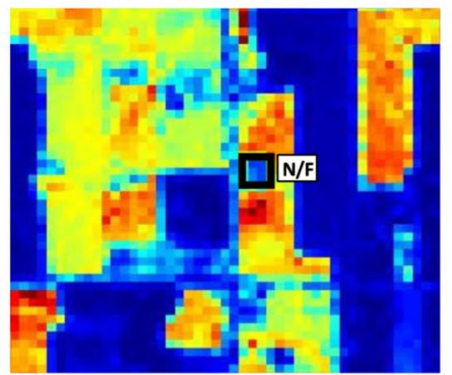

WE2 - June 18th 2013

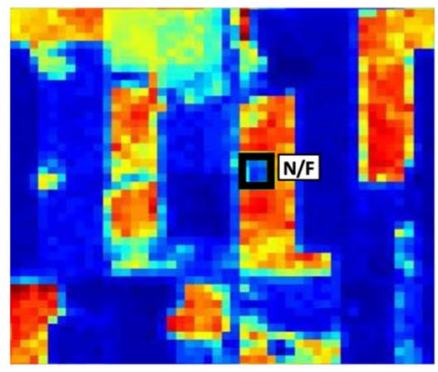

$0 \quad 200 \quad 400 \mathrm{~m}$

Fig. 10 Within-field scale maps of leaf chlorophyll content for the (a) corn fields, and (b) wheat fields, for different dates within the growing season. The black square box and adjoining no fertilizer (N/F) label highlights the control areas with no fertilization 
these findings; with relationships between modelled and measured leaf chlorophyll data of $\mathrm{R}^{2}=0.81$ and $\mathrm{R}^{2}=0.79$ for hyperspectral and Landsat data, respectively (Fig. 8). On the surface this result may appear surprising due to the reduced number of Landsat and the larger bandwidths relative to hyperspectral data. However, Thenkabail et al. (2004) argued that there is a high degree of redundancy of wavelength channels (Jacquemoud et al. 1995), and the volume of hyperspectral data can be reduced by $97 \%$ for vegetation studies, and identified seven optimal bands ( $495 \mathrm{~nm}, 555 \mathrm{~nm}, 655 \mathrm{~m}, 675 \mathrm{~nm}, 705 \mathrm{~nm}, 915 \mathrm{~nm}$, and $985 \mathrm{~nm})$. Croft et al. (2015) compared PROSPECT-modelled leaf chlorophyll from hyperspectral inputs to simulated bands for three other sensors (MERIS, MODIS and SPOT5 HRG), and found very strong linear relationships with hyperspectral results for Landsat, MODIS and MERIS bands (all sensors: $\left.\mathrm{R}^{2}=>0.96\right)$. A decreased performance using SPOT5 $\left(\mathrm{R}^{2}=0.88\right.$; bands $=545 \mathrm{~nm}$, $645 \mathrm{~nm}$ and $835 \mathrm{~nm}$ ) was likely due to the absence of a blue band and the very large red bandwidth (610-690 nm). In a comprehensive study, Shiklomanov et al. (2016) tested the inversion accuracy of PROSPECT using a Bayesian approach for simulated bands for ten different sensors. They found that the uncertainty and bias of leaf chlorophyll retrieval were relatively low for all sensors with the exception of AVHRR, which only has 3 bands, and relatively coarse wavebands (100-275 nm). The results from this research support these findings; indicating that a minimum presence of bands at key spectral inflection points (i.e. blue, green, red, NIR) is required. Importantly, given the presence of these bands, and a spectral bandwidth that is not too coarse $(<30 \mathrm{~nm})$, it is possible to model leaf chlorophyll content from multispectral data.

\section{Physically-based modelling approaches outperform empirical methods}

The two modelling approaches demonstrate the ability to map within field variability in leaf chlorophyll content, with physically-based methods presenting the stronger results $\left(\mathrm{R}^{2}=0.64, \mathrm{p}<0.001\right)$, compared to the best performing VI $\left(\right.$ GNDVI, $\left.\mathrm{R}^{2}=0.59, \mathrm{p}<0.001\right)$. It is well documented, that empirical vegetation indices are limited by their lack of transferability, across species, sites and time (Croft et al. 2014). This lack of transferability is because they fail to explicitly account for variations in canopy structure, solar geometry and associated changes in canopy BRDF and multiple scattering and background reflectance contributions. As shown in this research, including information on image acquisition conditions, canopy architecture and an independent, variable source of LAI, allows the implementation of the algorithm across different species and paves the way to its application across larger spatial extents. Despite the good performance of the physically-based approach, it is also worth recognising that these methods also have some limitations. The main source of uncertainty arises from inaccurate parameterization, and the need to have some a priori constraint to overcome the ill-posed problem (Ustin et al. 2009). Whilst some parameterisations may be treated as variable parameters, such as LAI and solar/viewing zenith angles, other canopy architectural values are more difficult to derive remotely. Variations in leaf angle distribution within a growing season, and between crop species and cultivars may lead to uncertainties in the retrieved leaf chlorophyll values. Studies have highlighted that for the same species, different development stages, crop genotypes and population densities can have widely different angular distribution of leaves (Vincini et al. 2016). 


\section{Multispectral chlorophyll inversion methods can be operationally used to inform nitrogen management}

The close relationship between chlorophyll and nitrogen, (Sage et al. 1987), offers an operational approach to quantifying crop nutritional status remotely, through the estimation of chlorophyll content. The 'crop nitrogen requirement' (CNR)) describes the relationship between canopy green area and the above-ground $\mathrm{N}$ content per unit of ground area. For UK-grown winter wheat, it is approximately $3 \mathrm{~g}$ nitrogen per $\mathrm{m}^{2}$ green area (Pask et al. 2012; Sylvester-Bradley et al. 1990). Deriving a quantitative measure of chlorophyll content at fine spatial scales, means that it possible to target fertiliser application to maintain crop nitrogen at a suitable level throughout the growing season. The finding that multispectral reflectance data can be used for chlorophyll content estimation not only enables the use of multispectral satellite sensors, but also UAV-based sensors; therefore providing an operational means of monitoring crop management to local-scale agricultural practioners. Hyperspectral imaging cameras are currently limiting in their size and cost for drone-based applications, whereas multispectral sensors (i.e. Tetracam Micro-MCA or modified infrared cameras) are available at relatively low cost. Given a suitable graphical user interface, a physically-based UAV approach may also allow agricultural managers to set some a priori information using 'on the ground' information, such as LiDF, soil wetness and species type, which should improve the accuracy of mapping further

\section{Conclusion}

This research demonstrates the potential of using multispectral reflectance data for monitoring sub-field scale spatial variability in leaf chlorophyll content, in order to optimise nitrogen fertiliser management. The results show that physically-based retrieval algorithms outperform empirical methods $\left(\mathrm{R}^{2}=0.64\right.$ and $\mathrm{R}^{2}=0.59$, respectively), due to their explicit consideration of confounding factors such as solar/view zenith angle and LAI that also affect canopy reflectance. However, the different vegetation indices also show considerable variation in prediction accuracy ranging from $\mathrm{R}^{2}=0.59$ (GNDVI) to $\mathrm{R}^{2}=0.03$ (BGI), demonstrating the need to be cautious in selecting an appropriate vegetation index. This research provides an operational basis for modelling within-field variations in leaf chlorophyll content as an indicator of plant nitrogen stress using fine spatial resolution Landsat-8 data. The findings also pave the way for using other multispectral sensors, including drone-mounted sensors, within a physically-based framework for precision agriculture applications.

Open Access This article is distributed under the terms of the Creative Commons Attribution 4.0 International License (http://creativecommons.org/licenses/by/4.0/), which permits unrestricted use, distribution, and reproduction in any medium, provided you give appropriate credit to the original author(s) and the source, provide a link to the Creative Commons license, and indicate if changes were made. 


\section{References}

Atzberger, C., Jarmer, T., Schlerf, M., Kötz, B., \& Werner, W. (2013). Retrieval of wheat bio-physical attributes from hyperspectral data and SAILH + PROSPECT radiative transfer model. In: Proceedings of the 3rd EARSeL Workshop on imaging spectroscopy (pp. 473-482). Citeseer.

Blackburn, G. A., \& Ferwerda, J. G. (2008). Retrieval of chlorophyll concentration from leaf reflectance spectra using wavelet analysis. Remote Sensing of Environment, 112(4), 1614-1632.

Chen, M. (2014). Chlorophyll modifications and their spectral extension in oxygenic photosynthesis. Annual Review of Biochemistry, 83(1), 317-340.

Chen, J. M., Pavlic, G., Brown, L., Cihlar, J., Leblanc, S. G., White, H. P., et al. (2002). Derivation and validation of Canada-wide coarse-resolution leaf area index maps using high-resolution satellite imagery and ground measurements. Remote Sensing of Environment, 80(1), 165-184.

Chen, J. M., Plummer, P. S., Rich, M., Gower, S. T., \& Norman, J. M. (1997). Leaf area index measurements. Journal of Geophysical Research, 102(D24), 29-429.

Combal, B., Baret, F., Weiss, M., Trubuil, A., Macé, D., Pragnère, A., et al. (2003). Retrieval of canopy biophysical variables from bidirectional reflectance using prior information to solve the ill-posed inverse problem. Remote Sensing of Environment, 84(1), 1-15.

Croft, H., \& Chen, J. M. (2018). Leaf pigment content. In S. Liang (Ed.), Comprehensive remote sensing (pp. 117-142). Oxford: Elsevier.

Croft, H., Chen, J. M., Luo, X., Bartlett, P., Chen, B., \& Staebler, R. M. (2017). Leaf chlorophyll content as a proxy for leaf photosynthetic capacity. Global Change Biology, 23(9), 1365-2486.

Croft, H., Chen, J., \& Noland, T. (2014a). Stand age effects on Boreal forest physiology using a long timeseries of satellite data. Forest Ecology and Management, 328, 202-208.

Croft, H., Chen, J. M., Wang, R. Mo, G., Luo, S., Luo, X., He, L. Gonsamo, A. Arabian, J., Zhang, Y., Simic, A., Noland, T. L., He, Y., Homolová, L., Malenovský, Z., Yi, Q., Beringer, J., Amiri, R., Hutley, L., Arellano, P., Stahl, C., \& Bonal, D. (in press). The global distribution of leaf chlorophyll content. Remote Sensing of Environment.

Croft, H., Chen, J. M., \& Zhang, Y. (2014b). The applicability of empirical vegetation indices for determining leaf chlorophyll content over different leaf and canopy structures. Ecological Complexity, 17, $119-130$.

Croft, H., Chen, J. M., Zhang, Y., \& Simic, A. (2013). Modelling leaf chlorophyll content in broadleaf and needle leaf canopies from ground, CASI, Landsat TM 5 and MERIS reflectance data. Remote Sensing of Environment, 133, 128-140.

Croft, H., Chen, J., Zhang, Y., Simic, A., Noland, T., Nesbitt, N., et al. (2015). Evaluating leaf chlorophyll content prediction from multispectral remote sensing data within a physically-based modelling framework. ISPRS Journal of Photogrammetry and Remote Sensing, 102, 85-95.

Danner, M., Berger, K., Wocher, M., Mauser, W., \& Hank, T. (2017). Retrieval of biophysical crop variables from multi-angular canopy spectroscopy. Remote Sensing, 9(7), 726.

Darvishzadeh, R., Skidmore, A., Schlerf, M., \& Atzberger, C. (2008). Inversion of a radiative transfer model for estimating vegetation LAI and chlorophyll in a heterogeneous grassland. Remote Sensing of Environment, 112(5), 2592-2604.

de Wit, C. T. (1965). Photosynthesis of leaf canopies. Wageningen: Pudoc.

Demarez, V., \& Gastellu-Etchegorry, J. P. (2000). A modeling approach for studying forest chlorophyll content. Remote Sensing of Environment, 71(2), 226-238.

Dong, T., Liu, J., Qian, B., Jing, Q., Croft, H., Chen, J., et al. (2017). Deriving maximum light use efficiency from crop growth model and satellite data to improve crop biomass estimation. IEEE Journal of Selected Topics in Applied Earth Observations and Remote Sensing, 10(1), 104-117.

Du, S., Liu, L., Liu, X., \& Hu, J. (2017). Response of canopy solar-induced chlorophyll fluorescence to the absorbed photosynthetically active radiation absorbed by chlorophyll. Remote Sensing, 9(9), 911.

Fang, F. (2015). The retrieval of leaf inclination angle and leaf area index in maize. University of Twente Faculty of Geo-Information and Earth Observation (ITC).

Feret, J. B., François, C., Asner, G. P., Gitelson, A. A., Martin, R. E., Bidel, L. P. R., et al. (2008). PROSPECT-4 and 5: advances in the leaf optical properties model separating photosynthetic pigments. Remote Sensing of Environment, 112(6), 3030-3043.

Gitelson, A. A., Gritz, Y., \& Merzlyak, M. N. (2003). Relationships between leaf chlorophyll content and spectral reflectance and algorithms for non-destructive chlorophyll assessment in higher plant leaves. Journal of Plant Physiology, 160(3), 271-282.

Gitelson, A. A., Viña, A., Ciganda, V., Rundquist, D. C., \& Arkebauer, T. J. (2005). Remote estimation of canopy chlorophyll content in crops. Geophysical Research Letters, 32(8), 1-4. 
Haboudane, D., Miller, J. R., Pattey, E., Zarco-Tejada, P. J., \& Strachan, I. B. (2004). Hyperspectral vegetation indices and novel algorithms for predicting green LAI of crop canopies: modeling and validation in the context of precision agriculture. Remote Sensing of Environment, 90(3), 337-352.

Haboudane, D., Miller, J. R., Tremblay, N., Zarco-Tejada, P. J., \& Dextraze, L. (2002). Integrated narrow-band vegetation indices for prediction of crop chlorophyll content for application to precision agriculture. Remote Sensing of Environment, 81(2-3), 416-426.

Haboudane, D., Tremblay, N., Miller, J. R., \& Vigneault, P. (2008). Remote estimation of crop chlorophyll content using spectral indices derived from hyperspectral data. IEEE Transactions on Geoscience and Remote Sensing, 46(2), 423-437.

Hosoi, F., \& Omasa, K. (2009). Estimating vertical plant area density profile and growth parameters of a wheat canopy at different growth stages using three-dimensional portable lidar imaging. ISPRS Journal of Photogrammetry and Remote Sensing, 64(2), 151-158.

Houborg, R., McCabe, M., Cescatti, A., Gao, F., Schull, M., \& Gitelson, A. (2015a). Joint leaf chlorophyll content and leaf area index retrieval from Landsat data using a regularized model inversion system (REGFLEC). Remote Sensing of Environment, 159, 203-221.

Houborg, R., McCabe, M. F., Cescatti, A., \& Gitelson, A. A. (2015b). Leaf chlorophyll constraint on model simulated gross primary productivity in agricultural systems. International Journal of Applied Earth Observation and Geoinformation, 43, 160-176.

Huang, W., Niu, Z., Wang, J., Liu, L., Zhao, C., \& Liu, Q. (2006). Identifying crop leaf angle distribution based on two-temporal and bidirectional canopy reflectance. IEEE Transactions on Geoscience and Remote Sensing, 44(12), 3601-3608.

Huete, A. R. (1988). A soil-adjusted vegetation index (SAVI). Remote Sensing of Environment, 25(3), 295-309.

Jackson, R. D., \& Pinter, P. J., Jr. (1986). Spectral response of architecturally different wheat canopies. Remote Sensing of Environment, 20(1), 43-56.

Jacquemoud, S., Bacour, C., Poilvé, H., \& Frangi, J. P. (2000). Comparison of four radiative transfer models to simulate plant canopies reflectance: direct and inverse mode. Remote Sensing of Environment, 74(3), 471-481.

Jacquemoud, S., \& Baret, F. (1990). PROSPECT: a model of leaf optical properties spectra. Remote Sensing of Environment, 34(2), 75-91.

Jacquemoud, S., Baret, F., Andrieu, B., Danson, F. M., \& Jaggard, K. (1995). Extraction of vegetation biophysical parameters by inversion of the PROSPECT + SAIL models on sugar beet canopy reflectance data. Application to TM and AVIRIS sensors. Remote Sensing of Environment, 52(3), 163-172.

Jacquemoud, S., Verhoef, W., Baret, F., Bacour, C., Zarco-Tejada, P. J., Asner, G. P., et al. (2009). PROSPECT + SAIL models: a review of use for vegetation characterization. Remote Sensing of Environment, 113, S56-S66.

Jiang, Z., Huete, A. R., Didan, K., \& Miura, T. (2008). Development of a two-band enhanced vegetation index without a blue band. Remote Sensing of Environment, 112(10), 3833-3845.

Jordan, C. F. (1969). Derivation of leaf area index from quality of light on the forest floor. Ecology, 50(4), 663-666.

Kempeneers, P., Zarco-Tejada, P. J., North, P. R. J., de Backer, S., Delalieux, S., Sepulcre-Cantó, G., et al. (2008). Model inversion for chlorophyll estimation in open canopies from hyperspectral imagery. International Journal of Remote Sensing, 29(17-18), 5093-5111.

Kimes, D. S., Knyazikhin, Y., Privette, J. L., Abuelgasim, A. A., \& Gao, F. (2000). Inversion methods for physically-based models. Remote Sensing Reviews, 18(2-4), 381-439.

le Maire, G., François, C., Soudani, K., Berveiller, D., Pontailler, J. Y., Bréda, N., et al. (2008). Calibration and validation of hyperspectral indices for the estimation of broadleaved forest leaf chlorophyll content, leaf mass per area, leaf area index and leaf canopy biomass. Remote Sensing of Environment, 112(10), 3846-3864.

Li, F., Miao, Y., Hennig, S. D., Gnyp, M. L., Chen, X., Jia, L., et al. (2010). Evaluating hyperspectral vegetation indices for estimating nitrogen concentration of winter wheat at different growth stages. Precision Agriculture, 11(4), 335-357.

Liu, J., \& Moore, J. M. (1990). Hue image RGB colour composition. A simple technique to suppress shadow and enhance spectral signature. International Journal of Remote Sensing, 11(8), 1521-1530.

Malenovský, Z., Albrechtová, J., Lhotáková, Z., Zurita-Milla, R., Clevers, J., Schaepman, M., et al. (2006). Applicability of the PROSPECT model for Norway spruce needles. International Journal of Remote Sensing, 27(24), 5315-5340.

Monteith, J. (1969). Light interception and radiative exchange in crop stands. Agronomy-Faculty Publications. 
Moorthy, I., Miller, J. R., \& Noland, T. L. (2008). Estimating chlorophyll concentration in conifer needles with hyperspectral data: an assessment at the needle and canopy level. Remote Sensing of Environment, 112(6), 2824-2838.

Nguy-Robertson, A., Gitelson, A., Peng, Y., Viña, A., Arkebauer, T., \& Rundquist, D. (2012). Green leaf area index estimation in maize and soybean: combining vegetation indices to achieve maximal sensitivity. Agronomy Journal, 104(5), 1336-1347.

Niinemets, U., \& Sack, L. (2006). Structural determinants of leaf light-harvesting capacity and photosynthetic potentials. Progress in Botany, 67, 385-419.

Pask, A. J. D., Sylvester-Bradley, R., Jamieson, P. D., \& Foulkes, M. J. (2012). Quantifying how winter wheat crops accumulate and use nitrogen reserves during growth. Field Crops Research, 126, $104-118$.

Peng, S., Buresh, R. J., Huang, J., Zhong, X., Zou, Y., Yang, J., et al. (2010). Improving nitrogen fertilization in rice by sitespecific N management. A review. Agronomy for Sustainable Development, $30(3), 649-656$.

Peng, Y., Gitelson, A. A., Keydan, G., Rundquist, D. C., \& Moses, W. (2011). Remote estimation of gross primary production in maize and support for a new paradigm based on total crop chlorophyll content. Remote Sensing of Environment, 115(4), 978-989.

Penuelas, J., Baret, F., \& Filella, I. (1995). Semi-empirical indices to assess carotenoids/chlorophyll a ratio from leaf spectral reflectance. Photosynthetica, 31(2), 221-230.

Reid, S., Smit, B., Caldwell, W., \& Belliveau, S. (2007). Vulnerability and adaptation to climate risks in Ontario agriculture. Mitigation and Adaptation Strategies for Global Change, 12(4), 609-637.

Richardson, A. D., Duigan, S. P., \& Berlyn, G. P. (2002). An evaluation of noninvasive methods to estimate foliar chlorophyll content. New Phytologist, 153(1), 185-194.

Rondeaux, G., Steven, M., \& Baret, F. (1996). Optimization of soil-adjusted vegetation indices. Remote Sensing of Environment, 55(2), 95-107.

Roujean, J. L., \& Breon, F. M. (1995). Estimating PAR absorbed by vegetation from bidirectional reflectance measurements. Remote Sensing of Environment, 51(3), 375-384.

Rouse, J. W., Haas, R. H., Schell, J. A., \& Deering, D. W. (1973). Monitoring vegetation systems in the Great Plains with ERTS. Third ERTS Symposium, 1, 309-317.

Rütting, T., Aronsson, H., \& Delin, S. (2018). Efficient use of nitrogen in agriculture. Berlin: Springer.

Sage, R. F., Pearcy, R. W., \& Seemann, J. R. (1987). The nitrogen use efficiency of C3 and C4 plants III. Leaf nitrogen effects on the activity of carboxylating enzymes in Chenopodium album (L.) and Amaranthus retroflexus (L.). Plant Physiology, 85(2), 355-359.

Schwan, T. D., \& Elliott, K. A. (2010). Effects of diameter-limit by-laws on forestry practices, economics, and regional wood supply for private woodlands in southwestern Ontario. The Forestry Chronicle, $86(5), 623-635$.

Shiklomanov, A. N., Dietze, M. C., Viskari, T., Townsend, P. A., \& Serbin, S. P. (2016). Quantifying the influences of spectral resolution on uncertainty in leaf trait estimates through a Bayesian approach to RTM inversion. Remote Sensing of Environment, 183, 226-238.

Sinclair, T. R., \& Rufty, T. W. (2012). Nitrogen and water resources commonly limit crop yield increases, not necessarily plant genetics. Global Food Security, 1(2), 94-98.

Smith, R. C., Adams, J., Stephens, D. J., \& Hick, P. T. (1995). Forecasting wheat yield in a Mediterranean-type environment from the NOAA satellite. Australian Journal of Agricultural Research, 46(1), $113-125$.

Suits, G. H. (1971). The calculation of the directional reflectance of a vegetative canopy. Remote Sensing of Environment, 2, 117-125.

Sylvester-Bradley, R., Stokes, D., \& Scott, R. (1990). A physiological analysis of the diminishing responses of winter wheat to applied nitrogen. I. Theory. Aspects of Applied Biology, 25, 277-287.

Thenkabail, P. S., Enclona, E. A., Ashton, M. S., \& Van Der Meer, B. (2004). Accuracy assessments of hyperspectral waveband performance for vegetation analysis applications. Remote Sensing of Environment, 91(3-4), 354-376.

Tilman, D., Cassman, K. G., Matson, P. A., Naylor, R., \& Polasky, S. (2002). Agricultural sustainability and intensive production practices. Nature, 418,671 .

Ustin, S. L., Gitelson, A. A., Jacquemoud, S., Schaepman, M., Asner, G. P., Gamon, J. A., et al. (2009). Retrieval of foliar information about plant pigment systems from high resolution spectroscopy. Remote Sensing of Environment, 113(1), S67-S77.

Verhoef, W. (1984). Light scattering by leaf layers with application to canopy reflectance modeling: the SAIL model. Remote Sensing of Environment, 16(2), 125-141.

Vincini, M., Calegari, F., \& Casa, R. (2016). Sensitivity of leaf chlorophyll empirical estimators obtained at Sentinel-2 spectral resolution for different canopy structures. Precision Agriculture, 17(3), 313-331. 
Vincini, M., \& Frazzi, E. (2011). Comparing narrow and broad-band vegetation indices to estimate leaf chlorophyll content in planophile crop canopies. Precision Agriculture, 12(3), 334-344.

Wang, Q.-C., Niu, Y.-Z., Xu, Q.-Z., Wang, Z.-X., \& Zhang, X.-Q. (1995). Relationship between plant type and canopy apparent photosynthesis in maize (Zea mays L.). Biologia Plantarum, 37(1), 85-91.

Wellburn, A. R. (1994). The spectral determination of chlorophylls a and b, as well as total carotenoids, using various solvents with spectrophotometers of different resolution. Journal of Plant Physiology, 144(3), 307-313.

Wu, C., Niu, Z., Tang, Q., \& Huang, W. (2008). Estimating chlorophyll content from hyperspectral vegetation indices: modeling and validation. Agricultural and Forest Meteorology, 148(8-9), 1230-1241.

Wu, C., Wang, L., Niu, Z., Gao, S., \& Wu, M. (2010). Nondestructive estimation of canopy chlorophyll content using Hyperion and Landsat/TM images. International Journal of Remote Sensing, 31(8), 2159-2167.

Yanli, L., Shaokun, L., Jihua, W., Carol, J. L., Ruizhi, X., \& Zhijie, W. (2007). Differentiating wheat varieties with different leaf angle distributions using NDVI and canopy cover. New Zealand Journal of Agricultural Research, 50(5), 1149-1156.

Zarco-Tejada, P. J., Berjón, A., López-Lozano, R., Miller, J., Martín, P., Cachorro, V., et al. (2005). Assessing vineyard condition with hyperspectral indices: leaf and canopy reflectance simulation in a rowstructured discontinuous canopy. Remote Sensing of Environment, 99(3), 271-287.

Zarco-Tejada, P. J., Miller, J. R., Harron, J., Hu, B., Noland, T. L., Goel, N., et al. (2004). Needle chlorophyll content estimation through model inversion using hyperspectral data from boreal conifer forest canopies. Remote Sensing of Environment, 89(2), 189-199.

Zhang, Y., Chen, J. M., Miller, J. R., \& Noland, T. L. (2008). Leaf chlorophyll content retrieval from airborne hyperspectral remote sensing imagery. Remote Sensing of Environment, 112(7), 3234-3247.

Zhang, Y., Chen, J. M., \& Thomas, S. C. (2007). Retrieving seasonal variation in chlorophyll content of overstory and understory sugar maple leaves from leaf-level hyperspectral data. Canadian Journal of Remote Sensing, 33(5), 406-415.

Publisher's Note Springer Nature remains neutral with regard to jurisdictional claims in published maps and institutional affiliations.

\section{Affiliations}

\section{Holly Croft ${ }^{1,2} \mathbb{D}$. Joyce Arabian ${ }^{1,3} \cdot$ Jing M. Chen ${ }^{1} \cdot$ Jiali Shang $^{4} \cdot$ Jiangui Liu $^{4}$}

1 Department of Geography, University of Toronto, 100 St. George Street, Toronto, ON M5S 3G3, Canada

2 Department of Animal and Plant Sciences, University of Sheffield, Western Bank, Sheffield S10 2TN, UK

3 WWF-Canada, 410 Adelaide Street W, Toronto, ON M5V 1S8, Canada

4 Agriculture and Agri-Food Canada, Ottawa Research and Development Centre, Ottawa, ON K1A 0C6, Canada 